\title{
Cryosphere Applications
}

\author{
I. Hajnsek, G. Parrella, A. Marino, T. Eltoft, M. Necsoiu, L. Eriksson, \\ and M. Watanabe
}

\begin{abstract}
Synthetic aperture radar (SAR) provides large coverage and high resolution, and it has been proven to be sensitive to both surface and near-surface features related to accumulation, ablation, and metamorphism of snow and firn. Exploiting this sensitivity, SAR polarimetry and polarimetric interferometry found application to land ice for instance for the estimation of wave extinction (which relates to sub surface ice volume structure) and for the estimation of snow water equivalent (which relates to snow density and depth). After presenting these applications, the Chapter proceeds by reviewing applications of SAR polarimetry to sea ice for the classification of different ice types, the estimation of thickness, and the characterisation of its surface. Finally, an application to the characterisation of permafrost regions is
\end{abstract}

\footnotetext{
I. Hajnsek ( $₫)$

Microwaves and Radar Institute, German Aerospace Center (DLR), Oberpfaffenhofen, Germany

Institute of Environmental Engineering, Swiss Federal Institute of Technology Zurich (ETH Zurich), Zürich, Switzerland

e-mail: irena.hajnsek@dlr.de

G. Parrella

Microwave and Radar Institute, German Aerospace Center (DLR), Wessling, Germany
}

A. Marino

Biological and Environmental Sciences, University of Stirling, Stirling, UK

T. Eltoft

UiT the Arctic University of Norway, Troms $\emptyset$, Norway

\section{Necsoiu}

Surveillance and Geolocation Department, Southwest Research Institute, San Antonio, TX, USA

\section{Eriksson}

Department of Space, Earth and Environment, Chalmers University of Technology, Gothenburg, Sweden

M. Watanabe

Department of Life Science and Engineering, Tokio Denki University, Tokio, Japan considered. For each application, the used (model-based) decomposition and polarimetric parameters are critically described, and real data results from relevant airborne campaigns and space borne acquisitions are reported.

\subsection{Introduction}

Over the last 30 years, the use of air- and space borne remote sensing has revolutionised glaciology through dramatic improvements in the scale and in the temporal and spatial resolutions of cryospheric observations. Remote sensing offers the possibility to cover large areas quickly and often at a low cost compared to more traditional methods. Many types of remote sensing can be useful for glacier studies including aerial photography and space borne sensors operating in the visible spectrum, gravimetry, passive microwave technology, and radar including satellite altimetry, scatterometry, and other active imaging systems.

However, the greatest advance has been the successful implementation of synthetic aperture radar (SAR). Over iceand snow-covered terrain, SAR has been proven to be sensitive to both surface and near-surface features related to accumulation, ablation, and metamorphism of snow and firn (material in the intermediate stage between snow and ice).

Land Ice In the last decade, the coherent combination of both interferometric and polarimetric observations has established PolInSAR as a viable technique for the extraction of geophysical parameters. However, the use of PolInSAR over glaciers to date is restricted to a small number of airborne studies due to the complexity of glacier environments and the inherent difficulties in validation. Temporal decorrelation and the limited polarimetric modes of spaceborne sensors limited the role of space-borne SAR data.

Nevertheless, the high spatial and temporal resolution and the (sensitive) observation space provide a considerable potential in PolSAR and PolInSAR applications over land ice. 
Land Ice - Snow Characterisation For land ice, the main issue today is the characterisation of the snow layer at the surface and the underlying ice volume. The snow layer can be characterised by means of two main parameters, the snow depth and density, which can be jointly measured through the snow water equivalent. Polarimetry can help to isolate the scattering contribution of the snow volume from the one of the underlying ground and with this it allows to establish a relation with the snow water equivalent.

Land Ice - Ice Extinction Another important parameter is the ice extinction that provides information about the ice volume structure and is, therefore, also an important indicator for changes in the ice volume. The main sensitivity is concentrated in the first 10-20 m of depth of the ice volume. The introduction of polarimetry in combination with interferometry represented a breakthrough for the retrieval of ice extinction.

Sea Ice The ice coverage of oceans plays a sensitive role in the interaction between the atmosphere and the water surface, while, at the same time, it affects sea traffic and human activities. In the northern hemisphere, significant economic components drive the need to study sea ice, in addition to the scientific reasons, while climatological and environmental aspects predominate the need for knowledge about the ice situation in the southern hemisphere.

The main interest lies in the information about sea ice extent, movement, and conditions. The formation of sea ice depends on a variety of environmental factors like temperature, wind, current, and water salinity. At the same time, sea ice undergoes a seasonal cycle and has several distinct stages of development. Polarisation diversity has shown to increase the information content of SAR imagery significantly and the benefits for sea ice monitoring have been recognised early; despite this, the amount of polarimetric SAR data of sea ice available today remains limited. Most of the research work in this domain has been based on airborne SAR data and later on images from ALOS-PALSAR and RADARSAT-2. Many of the early studies based on polarimetric SAR focused on the physics of scattering from sea ice and the resulting polarimetric signatures of ice types. Major investigations were made for sea ice-type classification using different algorithms.
Sea Ice - Classification The most used approach for sea ice characterisation is based on image segmentation algorithms applied on single, dual, or fully polarimetric SAR data. With the introduction of RADARSAT-2, fully polarimetric SAR images have been used on a wider basis in classification procedures improving segmentation performance of different ice types.

Sea Ice - Thickness For thin sea ice thickness is a sensitive parameter affecting the heat exchange between atmosphere and ocean. There is an increasing interest to better understand and quantify this relation within the climate system as well as to monitor and to model its state. During the last two decades, the sensitivity of active microwave sensors and their potential for thin sea ice thickness retrieval was intensively investigated, both empirically and theoretically. A simplified scattering solution for the rough surface case of polarised backscattering of thin sea ice has been established. In addition, a theoretical base for the relation of co-polarised polarimetric coefficients (co-pol ratio and phase difference, complex correlation coefficient) - being independent of surface roughness - to the thickness of thin sea ice was developed in L- and X-band.

Sea Ice - Surface Characterisation Sea ice surface roughness is another important parameter together with sea ice thickness for the thermodynamic exchange between atmosphere and ocean. Although not yet fully understood and quantified, sea ice surface roughness is used as an input parameter for weather prediction modelling. Several works consider surface roughness algorithms for bare surface applications, but only few studies investigate their use on sea ice surfaces. However, with fully polarimetric airborne sensors, first data sets were acquired to test and develop this application.

There are two main parties interested into cryosphere applications for either ecosystem change research or industrial interest (see Table 4.1). The main motivation is to infer the measured snow and ice parameters into ecosystem change models and use them as an input for climate change model predictions or have a commercial interest as for example securing continuous ship traffic roads.

Table 4.1 Polarimetric SAR applications in cryosphere: use and motivation

\begin{tabular}{l|l|l}
\hline (End) users & Application(s) & Interest/motivation \\
\hline \multirow{2}{*}{ Authorities/agencies research } & Snow characterisation & Justification of subsidies and fraud detection, acreage \\
\cline { 2 - 3 } & Retreat of glaciers & Control in regions suffering droughts or with scarce water resources \\
\cline { 2 - 3 } & Sea ice characterisation & Economic and market predictions, price regulations, etc. \\
\hline Commercial & Sea ice extend, movement, condition & Ship traffic road mapping \\
\hline
\end{tabular}




\subsection{Land Ice Extinction Estimation Using PollnSAR}

\subsubsection{Introduction, Motivation, and Literature Review}

Monitoring glaciers and ice sheets is a primary task to understand and quantify climate change. Mass balance is the most important descriptor of the health of a glacier and is the final objective of nearly all glacier monitoring studies. It expresses the total mass change of a glacier in 1 year and is computed by the algebraic sum of accumulation (all processes by which material is added to a glacier) and ablation (all processes by which snow or ice is lost from a glacier). Hence, mass balance is an important indicator of a glacier's likely response to climate change. There are several reasons why direct observations of mass balance are either impractical or too inaccurate to be of value, in which case it may be useful to measure a proxy variable that is qualitatively or quantitatively related to mass balance or to a change in mass balance. The two main existing approaches are to monitor or track changes in the extent of the various glacier facies (characterised by differing degrees of summer melt) and to make repeated observations of changes in the areal extent and terminus position of a glacier over time. Areal extent is still today best measured with optical imagery, although radar imagery has shown significant promise for facies classification.

Because dry snow is relatively transparent at microwave frequencies, end-of-summer conditions are preserved in winter SAR images and the different melting and freezing patterns of the various zones result in distinct radar backscatter properties. SAR imagery has been used to help delineate facies boundaries, although interpretation can be difficult as variations in backscatter are also caused by changes in the surface dielectric properties, roughness, and topography. The additional information provided by PolInSAR can help eliminate this ambiguity by separating surface and volume contributions and thus lead to a more accurate characterisation of melt extent. PolInSAR-derived glacier properties such as facies boundaries and the presence of melt features could thus be used as proxy indicators of changes in glacier mass balance and regional climate. Both facies and melt structures are related to the electromagnetic ice extinction through a variation of vertical density.

The estimation of a parameter such as extinction is of high relevance for glaciologists since it contains information on the density and internal structure of the ice:

- It is useful for characterising regions of greater or lesser volume scatter (Hoen 2001), and in turn increasing the accuracy of facies delineation and classification.
- It provides a better understanding of glacier dynamics, monitoring the extent of the various melt zones (facies) and mass balance fluctuations that may be occurring in the Polar Regions as a result of climatic changes (Davis and Poznyak 1993).

- Extinction also has implications on the accuracy of existing radar products, as knowledge of its temporal and spatial variability could help in correcting InSAR (Dall 2007) and radar altimeter-derived elevation maps which suffer from an extinction-dependent penetration bias (Jezek et al. 1994).

Despite the significant progress in determining the spatial extent of glaciers, in mapping surface features and in determining surface elevation, large uncertainties remain in estimating reliable glacier accumulation rates, ice thickness, subsurface structures and discharge rates. Consequently, even today it is challenging to grasp the structure of the ice volume with SAR remote sensing methods.

The first SAR images, taken in 1978 by Seasat (L-band), revealed the potential of SAR for identifying surface and subsurface features and in classifying the glacier zones (Bindschadler et al. 1987; Rott 1984). A significant step forward was done with the introduction of experimental fully polarimetric SAR systems. PolSAR data over alpine glaciers were provided by the SIR-C (1994) at C- and L-band (Mätzler et al. 1984).

SAR interferometry has been widely applied to measure glacier topography and displacements at accuracies of centimetres to metres (Dowdeswell et al. 1999; Massonnet and Feigl 1998; Mohr and Madsen 1996; Joughin et al. 1998). Preliminary investigations into the relation between interferometric coherence and the rate of extinction of the radar signal in ice were conducted in (Hoen 2001; Hoen and Zebker 2000) in which the ice was modelled as a homogeneous, lossy, and infinite scattering volume. However, polarimetric effects were not included in the coherence model.

The use of PolInSAR over glaciers is restricted to a small number of airborne studies (Dall et al. 2003, 2004; Stebler et al. 2005) due to temporal decorrelation and to the limited polarimetric modes of space-borne sensors, as well as to the complexity of glacier environments and to difficulties in validation. In (Stebler et al. 2005), the authors describe PolInSAR signatures at L- and P-band over an alpine glacier, although no model is suggested to explain polarisation dependencies in the backscatter and interferometric coherence. PolInSAR coherences at L-band over Greenland are presented in (Dall et al. 2003), and several models are considered in (Dall et al. 2004), although no physically model consistent with observed coherence magnitude and phase was found. Given the high resolution and multiple observables offered by PolInSAR on a pixel-by-pixel basis, there is 
considerable potential for its use in glaciological applications if a model relating observables to ice properties could be found.

In the recent literature, great attention has been given to model-based decomposition techniques. One of the first model-based polarimetric decomposition for ice was proposed in (Sharma et al. 2011). The main scattering contributions were assumed to come from a shallow snow-ice interface, the underlying possibly oriented ice volume (of dipole-shaped particles) and an oriented sastrugi field at the surface.

\subsubsection{Methodology}

The ice extinction estimation method used for this application was proposed in (Sharma 2010) and can be seen as made of two parts: model-based polarimetric decomposition and PolInSAR inversion procedure. The principal objective of the polarimetric decomposition is to break down the total scattering within one resolution cell into a sum of elementary scattering contributions and to associate a physical mechanism to each component. The advantage of the model-based approach is that it is based on the physics of radar scattering; hence the interpretation of its results is relatively straightforward (Van Zyl et al. 2008).

The considered decomposition technique assumes, in a more general case, that the total backscattering consists of three components: surface, volume, and oriented sastrugi field. Assuming that the mentioned contributions are uncorrelated, the combined covariance matrix is the sum of the three individual matrices plus a diagonal noise matrix $\mathbf{N}$ :

$$
\mathbf{C}_{\text {tot }}=\mathbf{C}_{g}+\mathbf{C}_{v}+\mathbf{C}_{s}+\mathbf{N}
$$

where $\mathbf{C}_{g}, \mathbf{C}_{v}$, and $\mathbf{C}_{s}$ indicate the covariance matrices of the surface, volume, and sastrugi contribution, respectively.

The surface scattering is postulated to originate from a slightly rough snow-ice interface and modelled using the first-order Small Perturbation Model (SPM). The overlying dry snow layer is assumed to be transparent at long wavelength (L- and P-band) and only responsible for refraction of the incident wave.

The ice volume component is believed to be due to a dominant scattering mechanism related to ice crystals or ice inclusions (ice pipes and lenses). Consequently, the ice mass is modelled as an infinite homogeneous volume of identically shaped and sized scatterers. For simplicity, the scatterers are assumed to be thin randomly oriented dipoles. Transmission and propagation effects are also introduced to model a more realistic scenario.
A third relevant scattering contribution is expected to originate from a shallow oriented sastrugi field. This consists of streamlined snow dunes formed by wind erosion and deposition on the snow surface. It is generally oriented parallel to the main wind direction, and its size ranges from one to a few metres. An oriented sastrugi field is then modelled as an oriented volume of dipoles where all scatterers are contained in the plane of the air-snow interface.

The importance of possible multiple scattering mechanisms has been investigated by analysing circular ratio values (RR/RL and LL/RL) observed in the dataset selected for this showcase. The available L-band and P-band acquisitions show low circular ratio, with values ranging between 0.2 and 0.4 . Only in some cases at L-band, it reaches values higher than 1.0 in the extreme far range region. This general behaviour can be interpreted as an indicator of the low importance of multiple scattering, which was consequently neglected in the model.

Decomposition results are used to estimate surface-tovolume ratios $\mu$ (where the surface contribution includes the sastrugi component) for each available polarimetric channel in order to isolate the volume backscattering contribution.

In a second step, the outcome of the polarimetric decomposition is used as input in an interferometric coherence model, which is finally inverted to retrieve ice extinction for each polarimetric channel. In detail, surface-to-volume ratios are employed to estimate the volumetric coherence $\gamma_{\mathrm{Vol}}$ from the total InSAR coherence $\gamma$ of the corresponding channel using the following relations:

$$
\begin{gathered}
\gamma=e^{j \phi} \gamma_{\mathrm{SNR}} \gamma_{\text {range }} \gamma_{z} \\
\gamma_{z}=\frac{\gamma_{\mathrm{Vol}}\left(k_{e}\right)+\mu}{1+\mu}
\end{gathered}
$$

where $\phi$ is a topographic phase term, $\gamma_{\mathrm{SNR}}$ is the coherence term due to SNR decorrelation, $\gamma_{\text {range }}$ represents the coherence due to range spectral decorrelation, and $\gamma_{z}$ the term dependent only on the vertical distribution of the scatterers. In (4.3), $\mu$ is the estimated surface-to-volume ratio, and $\gamma_{\mathrm{Vol}}\left(k_{e}\right)$ the volume decorrelation expressed as function of the extinction coefficient $k_{e}$ to be estimated. In order to account for the propagation within the ice volume, the vertical wavenumber $k_{z}$ has been modified by considering the dielectric constant of ice.

The range spectral decorrelation $\left(\gamma_{\text {range }}\right)$ and SNR decorrelation $\left(\gamma_{\mathrm{SNR}}\right)$ can be separately estimated according to (Hoen and Zebker 2000; Zebker and Villasenor 1992), respectively. At this point, the extinction coefficient can be inverted from $\gamma_{\mathrm{Vol}}$ for each polarisation and baseline. 


\subsubsection{Experimental Results}

Test sites and corresponding radar and validation data sets selected for the generation of showcases on land ice extinction estimation are summarised in Table 4.2 and further described in the Appendix.

As shown in Fig. 4.1, surface-to-volume scattering ratios estimated by means of the polarimetric decomposition are used in combination with PolInSAR coherences and the infinite-uniform-volume-underground model to determine the ice extinction coefficient. The PolInSAR inversion procedure is separately applied to each polarimetric channel. A spatial averaging window of 100 effective looks is used to compute interferometric coherences, corresponding to an approximately square window of $20 \times 20 \mathrm{~m}$ in ground range - azimuth geometry. Results from multiple baselines are combined by eliminating solutions from extremely small baselines (which have no interferometric sensitivity) and from longer baselines more susceptible to insufficiencies in modelling. Results are then averaged from the remaining valid baselines on a pixel-by-pixel basis. For brevity, results of polarimetric decomposition and extinctions inversion are shown in the following only for ascending acquisitions for the Summit test site. Figures 4.2 and 4.3 show the

Table 4.2 Test sites and corresponding radar and validation data selected for the generation of showcases on land ice extinction estimation

\begin{tabular}{l|l|l}
\hline Application/product & Test site - Radar data & Reference data \\
\hline \multirow{2}{*}{ Land ice extinction estimation } & Summit, Austfonna, Svalbard & GPR profiles, meteorological data, snow pit \\
& Etonbreen, Austfonna, Svalbard & \\
\cline { 2 - 3 } & ICESAR 2007, E-SAR, L-/P-band full-pol & \\
\hline
\end{tabular}

Fig. 4.1 Workflow for extinction inversion using PolInSAR observables (Sharma 2010)

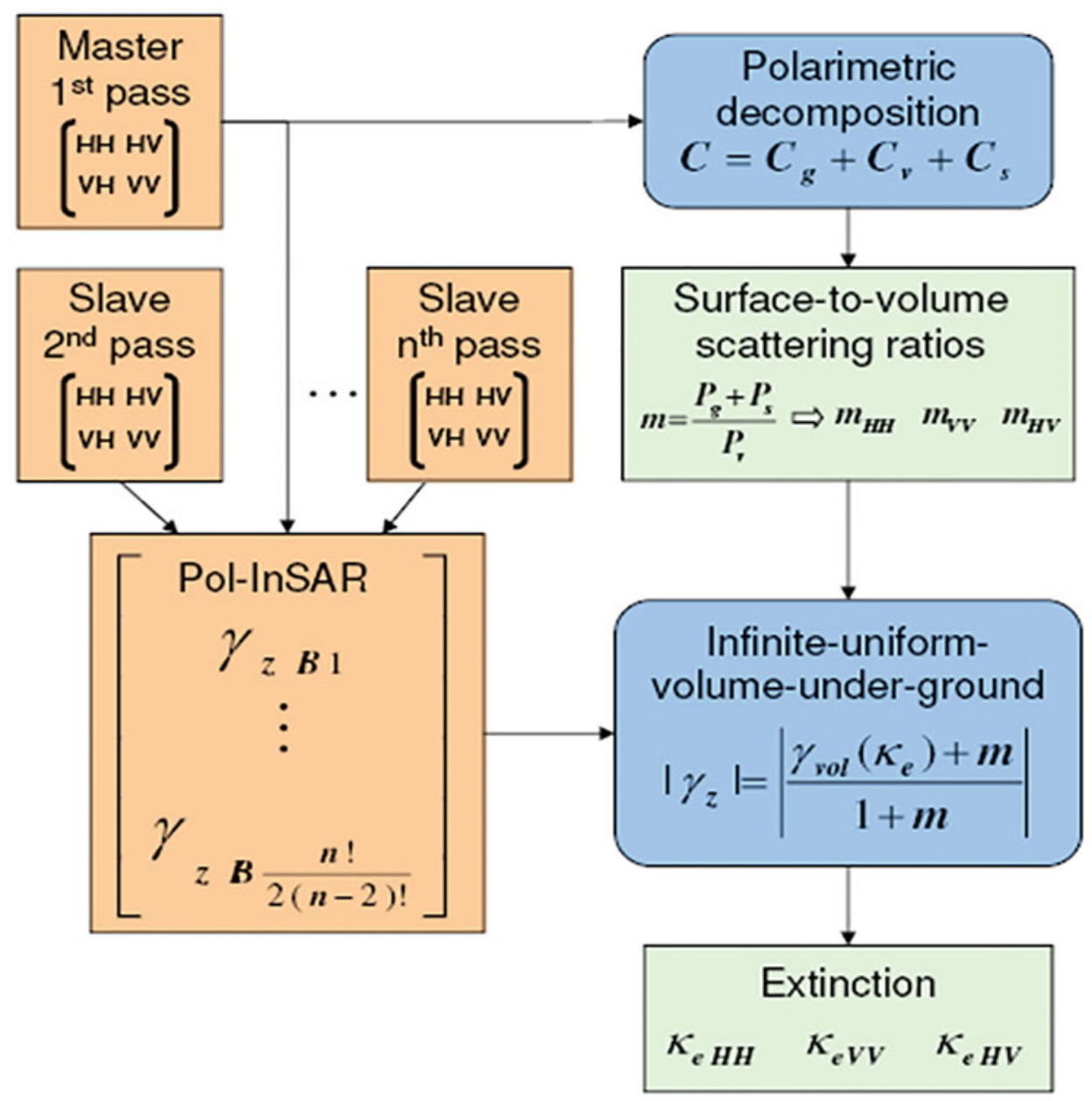

\section{SAR Data Models Derived}



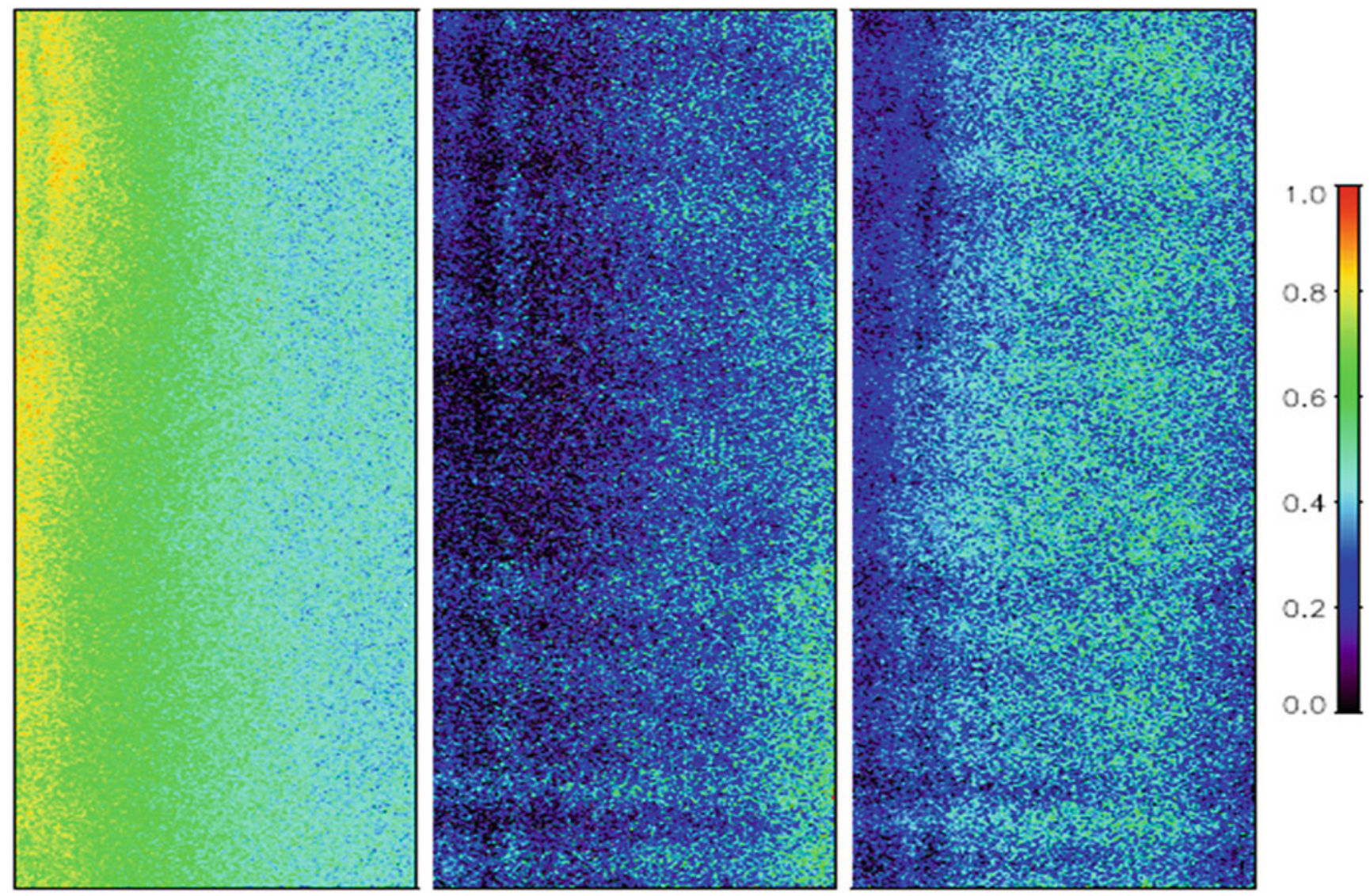

Fig. 4.2 Decomposed power contributions from L-band ascending acquisitions of March 2007, for the Summit test site. From left to right, surface, volume, and oriented sastrugi contributions are shown
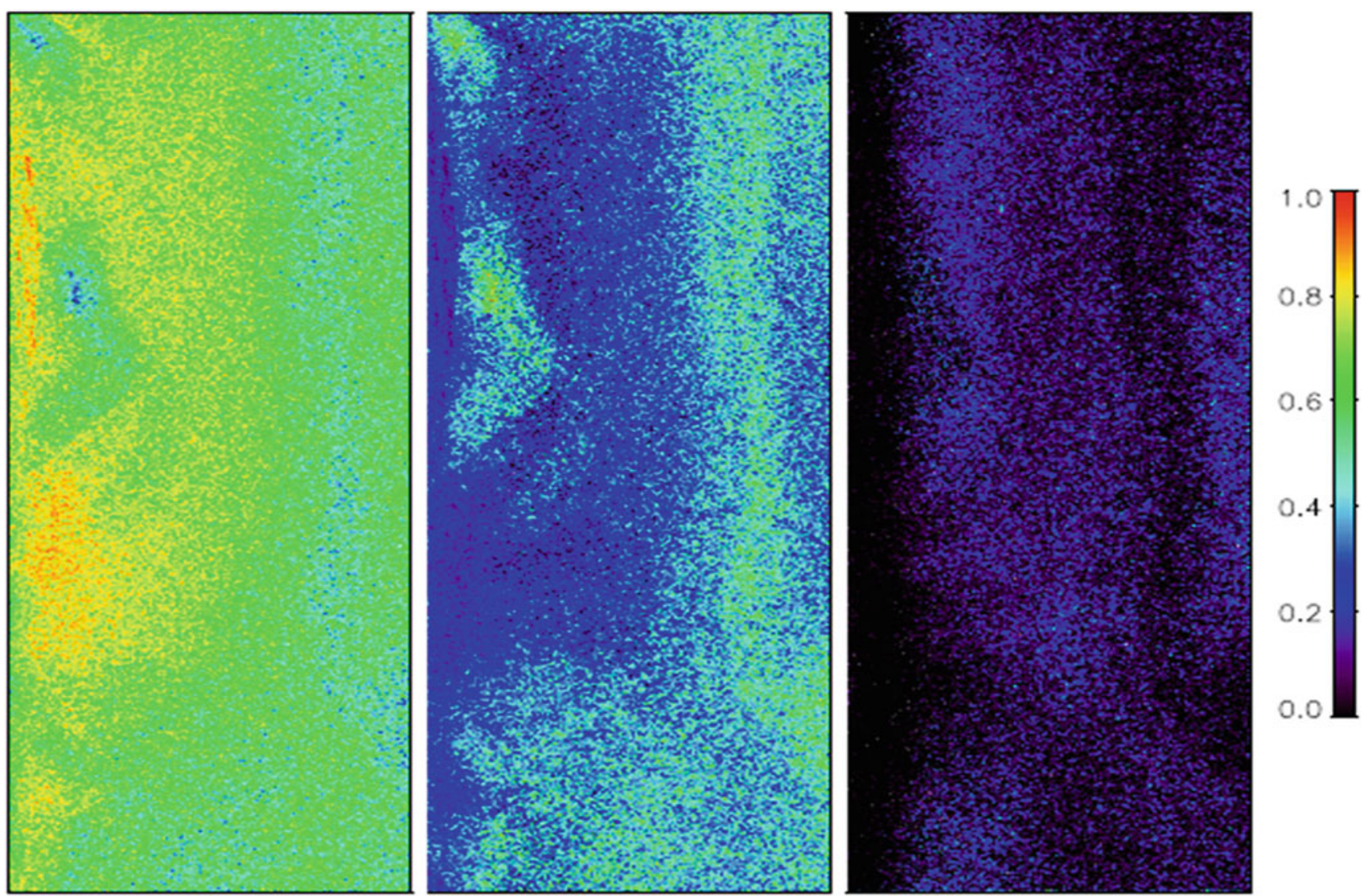

Fig. 4.3 Decomposed power contributions from P-band ascending acquisitions of March 2007, for the Summit test site. From left to right, surface, volume and oriented sastrugi contributions are reported 
decomposed powers for the surface, volume, and sastrugi contributions at L- and P-band, respectively, for the Summit test site. As expected, the surface contribution is generally higher in the near range, due to the steeper incidence angle, while it decreases for higher incidence angle at both frequencies. Interestingly, the estimated volume power is rather different at L- and P-band. In the first case, Fig. 4.2 shows a quite homogeneous image, with slight increase from the near to the far range, consistent with the behaviour of the surface component described above. Figure 4.3 depicts a rather different scenario for P-band as the volume component varies more within the scene. Areas characterised by higher volume contribution might be related to the presence of abundant melt features (ice pipes, lenses) located deeper in the firn layer, that can only be detected at P-band due to the enhanced penetration capability. Finally, decomposed sastrugi powers point out a stronger influence on L-band measurements than at P-band, confirming that longer wavelengths are more sensitive to the underlying ice volume.

A first validation of the estimated extinction values has been carried out by comparison with published laboratory experiments on pure ice from (Tiuri et al. 1984; Ulaby et al. 1986a; Dowdeswell and Drewry 2004; Warren and Brandt
2008). These studies report absorption extinction coefficients of 0.02 to $0.09 \mathrm{~dB} / \mathrm{m}$ at $\mathrm{L}$ - and P-band for temperatures ranging from -8 to $-5{ }^{\circ} \mathrm{C}$, with L-band extinctions slightly larger than P-band values. Extinctions derived at L-band from glacier ice samples include one study from the dry-zone of Antarctica yielding $0.29 \mathrm{~dB} / \mathrm{m}$ at $1.5 \mathrm{GHz}$ and $0.04 \mathrm{~dB} / \mathrm{m}$ at $0.9 \mathrm{GHz}$ (Holmlund et al. 2000) and a second study from the Canadian Arctic quoting a value of $0.05 \mathrm{~dB} / \mathrm{m}$ at $1.3 \mathrm{GHz}$ (Uratsuka et al. 1996). At P-band an extinction rate of $0.03 \mathrm{~dB} / \mathrm{m}$ was derived from GPR data in the percolation zone of central Greenland (Paden et al. 2007). Comparing these values to the experimentally derived results from the firn zone at Summit (see Fig. 4.4), the averaged L-band results from the Pol- InSAR model of around $0.1 \mathrm{~dB} / \mathrm{m}$ are reasonable when compared to (Holmlund et al. 2000), falling between the extinctions derived for 0.9 and $1.5 \mathrm{GHz}$. The L-band extinctions at Summit are somewhat higher than that quoted in (Uratsuka et al. 1996), although the glacier faces for (Uratsuka et al. 1996) is unknown, such that it may correspond to relatively pure ice such as in the ablation or superimposed ice zones without ice inclusions to introduce scattering loss. At P-band, there are higher extinctions $(>0.15 \mathrm{~dB} / \mathrm{m})$ in areas of concentrated potential melt
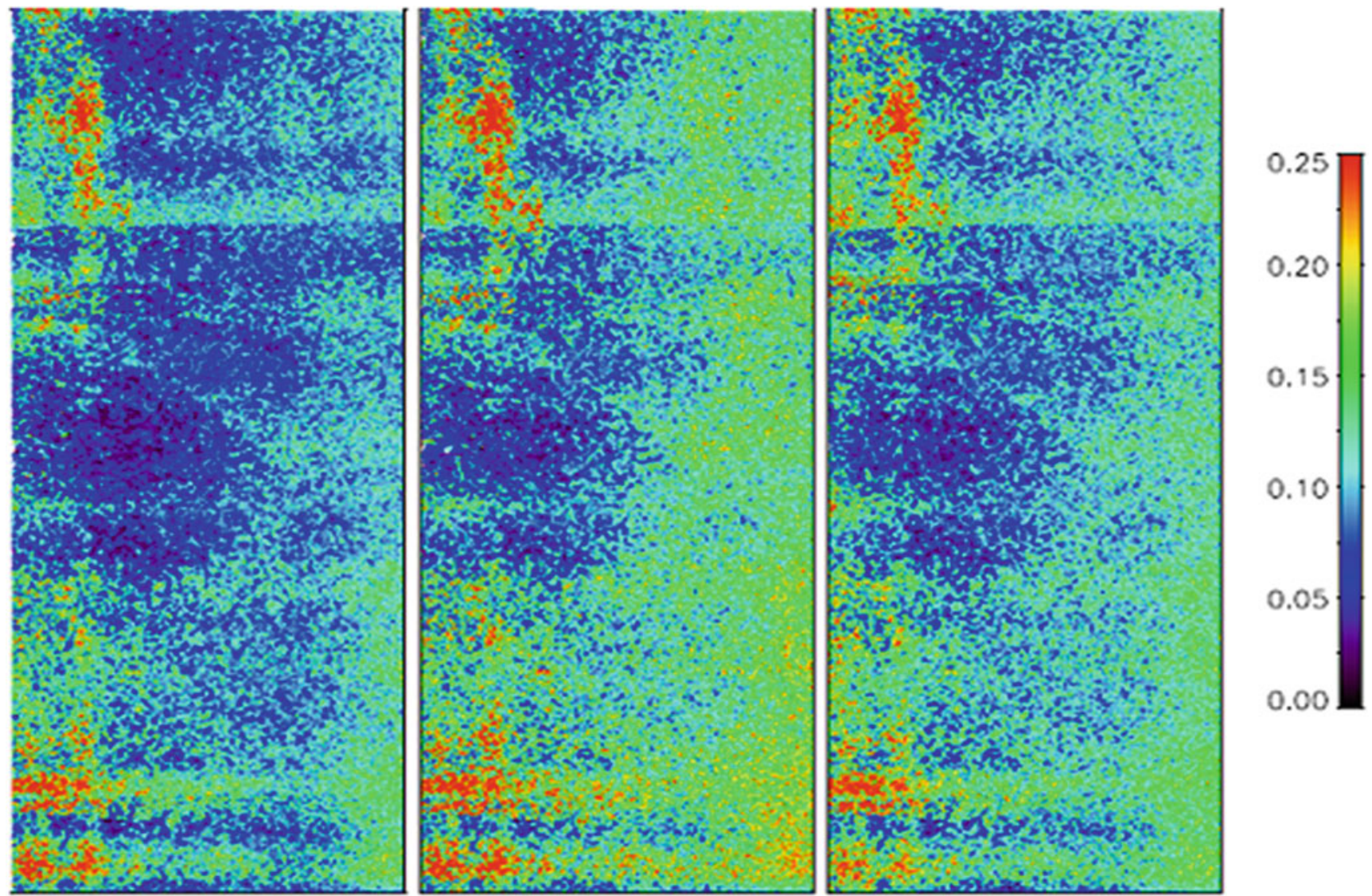

Fig. 4.4 Inverted extinctions $k_{e}[\mathrm{~dB} / \mathrm{m}]$ for $\mathrm{HH}$ (left), $\mathrm{VV}$ (middle), and $\mathrm{HV}$ (right) polarisations, from ascending L-band acquisitions of March 2007 over Summit 

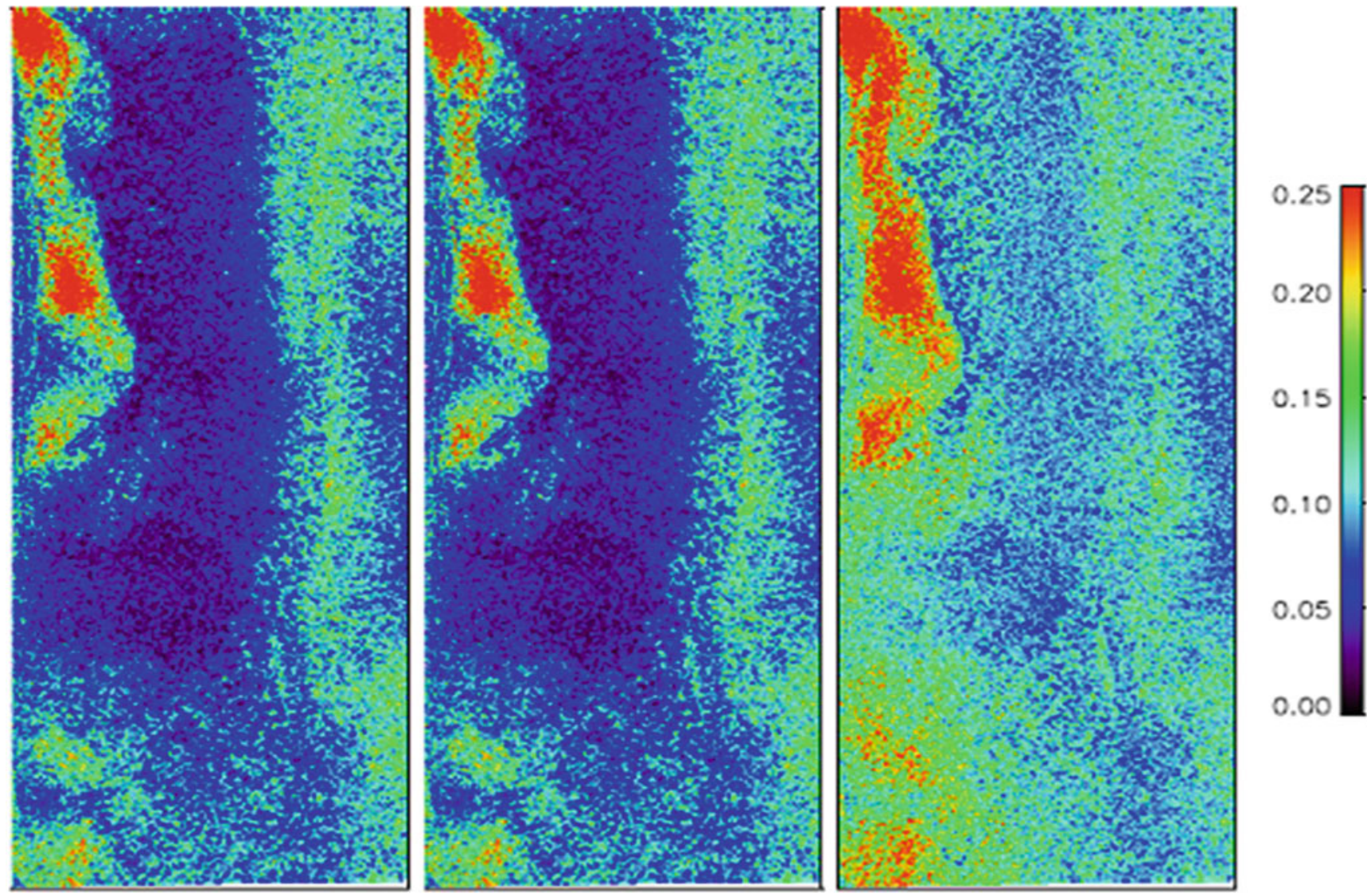

Fig. 4.5 Inverted extinctions $k_{e}[\mathrm{~dB} / \mathrm{m}]$ for $\mathrm{HH}$ (left), $\mathrm{VV}$ (middle) and $\mathrm{HV}$ (right) polarisations, from ascending P-band acquisitions of March 2007 over Summit

structures at Summit, but background values are approximately $0.05 \mathrm{~dB} / \mathrm{m}$ in Fig. 4.5 for the co-polarisations, in rough agreement with (Paden et al. 2007). At Etonbreen in the superimposed ice zone, extinctions at both L-band and P-band are lower than at Summit, with values close to $0.05 \mathrm{~dB} / \mathrm{m}$ at L-band and $0.04 \mathrm{~dB} / \mathrm{m}$ at P-band for the co-polarisations.

Only a relative comparison between the GPR and SAR data is possible, because of the differences in frequency, depth of integration (only around $10 \mathrm{~m}$ for the GPR data compared to the much deeper SAR penetration depths inverted from the estimated extinctions), and most significantly, differences in acquisition geometry. In fact, the GPR is nadir-looking and thus has a strong surface reflection component compared with the SAR side-looking backscatter. Nevertheless, a relative comparison of GPR backscattering coefficients with the SAR data was carried out in (Sharma 2010) to verify whether the volume scattering seen by the GPR is related to that from the inverted extinctions. However, better agreements were observed between inverted extinctions and GPR backscatter at L-band. This could indicate that the polarimetric decomposition was able to remove the surface contribution from the SAR data. At P-band, a worse agreement was found, probably because of the SAR's deeper penetrations, well below the range of the GPR data.

\subsubsection{Comparison with Single/Dual Polarisation Data}

For this application, a comparison with a dual-polarimetric case is not possible. As seen in Sect. 4.2.2, the employed methodology is based on a polarimetric-decomposition technique for which fully polarimetric SAR data are needed. Moreover, the complexity of the scattering mechanisms involved in an ice scenario still represents a very limiting factor for the development of further electromagnetic models. Consequently, there is still a lack of studies addressing ice extinction by means of SAR, and the adopted methodology represents one of the very few published works in this field.

\subsubsection{Discussion on the Role of Polarimetry, on the Maturity of the Application, and Conclusions}

The potential of SAR for ice extinction retrieval is due to its capability to penetrate into the ice masses for several tens of metres at long wavelengths. In addition, the typical sidelooking acquisition geometry of SAR sensors avoids strong echoes from glaciers surface like in the case of GPR, and the total backscatter results to be more related to the ice volume 
structure. In this sense, polarimetry has a crucial role in the understanding of the scattering mechanisms involved in this kind of scenario, and polarimetric model-based decomposition techniques are actually a very powerful tool to model and interpret SAR signatures. The advantage of model-based approaches is that they are based on the physics of the radar scattering and the characteristics of the investigated scenario; hence their interpretation turns very straightforward.

\subsection{Snow Water Equivalent Retrieval}

\subsubsection{Introduction, Motivation, and Literature Review}

Snow is a basic reservoir of water and a significant part of the Earth's population relies on seasonal snow-packs and glacier for their water supply (Barnett et al. 2005). Snow also represents a critical component of the global water cycle and climate system. Consequently, the global warming could have a severe impact on several aspects of our society. For this reason, spatially distributed information on snow accumulation rate, glaciers mass balance, lake ice, and sea ice are strongly required. In fact they became essential for the development of large-scale hydrological and climate models, in order to better understand the on-going changes and to predict future climate dynamics. In this sense, satellite missions are capable to provide global and systematic observations also over the Polar Regions, where the extreme climate makes in situ studies very challenging. For snow cover monitoring, snow water equivalent (SWE) is the primary parameter to estimate. SWE can be defined in units of $\mathrm{kg} / \mathrm{m}^{2}$ as the product of snow depth and density, or in units of $\mathrm{m}$ by normalising it to the water density $\left(\rho_{\text {water }}=1 \mathrm{~kg} / \mathrm{m}^{3}\right)$.

Microwave remote sensing overcomes several limiting factors, like weather and sun illumination dependence, affecting optical and infrared techniques. Its potential in monitoring snow cover properties is related to retrieval of the electromagnetic properties (e.g. dielectric constant) of snow. In the microwave range, snow exhibits well-defined spectral and polarimetric signatures related to its special dielectric proprieties which, in turn, depend on the micro- and macroscopic structure and geometry of the snowpack (Maetzler 1998). These characteristics make SAR suitable for studying and monitoring snow cover.

Due to the high penetration capability of microwaves (for frequencies up to X-band) and low attenuation of dry snow, a snowpack behaves as a quasi-transparent medium. In this case, the major scattering source is the snow/ground interface (Shi et al. 1993). Hence, X-band or higher frequency (e.g. Ku-band) SAR sensors are needed for snow depth measurement and snowpack characterisation because of their higher sensitivity (shorter wavelength) to the snowpack structure (Shi and Dozier 1993). Considering a typical snow cover scenario, several parameters influence the measured backscattering. The most significant include snow density and depth, grain size distribution, wetness, and their variation along depth as well as snow surface roughness underlying soil conditions (permittivity, roughness, and topography).

First investigations concerning snow parameter estimation by means of SAR have been addressed with single frequency and single polarisation (both $\mathrm{VV}$ and $\mathrm{HH}$ ) data mainly due to the restricted operation modes of early airborne and space borne SAR sensors (Guneriussen et al. 2001; Shi and Dozier 1995, 2000a, b). Several methods have been developed for snow cover mapping using multi-temporal SAR data. Time series C-band SAR data have been used to estimate SWE of a snow cover in the Appalachian Mountains in Southern Quebec (Bernier and Fortin 1998). The study revealed that the scattering from a shallow snow layer $(\mathrm{SWE}<20 \mathrm{~cm})$ is undetectable at C-band.

Several experiments have been conducted by using multifrequency (L-, C-, and X-band) and multi-polarisation radar backscatter data from the Shuttle Imaging Radar-C (SIR-C) mission to estimate snow density, depth, and particle size (Shi and Dozier 2000a, b). The retrieval approach was based on a physical model and provided reasonable estimates of SWE, validated with in situ measurements. Nevertheless, the estimation uncertainty remained large, probably due to the already mentioned smaller sensitivity of low frequencies to SWE than higher microwave frequencies. Recent modelling approaches indicate that combined observations at X-and $\mathrm{Ku}$-bands are more suitable for remote sensing of SWE (Shi 2006). In this sense, the dual-frequency COld REgions Hydrology High-resolution Observatory (CoReH2O) Candidate Mission was selected from the European Space Agency (ESA) for feasibility studies in the frame of the Earth Explorer Programme (European Space Agency 2008). The CoReH2O SWE retrieval procedure is based on the inversion of a two-layer (snow-over-ground) radiative transfer model, using measured dual polarisation ( $\mathrm{VV}$ and $\mathrm{VH}$ ) backscattering as input together with some a priori information (European Space Agency 2008). This procedure is specifically developed for open areas under the assumption of a dry snow cover.

In the last years, the availability of fully polarimetric space-borne X-band data (e.g. from TerraSAR-X) made possible first investigations on the potential of polarimetry in estimating snow cover properties from space. For this, a first polarimetric decomposition technique for a snow-cover scenario was proposed in (Pisciottano et al. 2011) to discriminate the scattering contribution of the snow-pack from the underlying ground, in order to extract the snow layers characteristics independently from the ground conditions. 


\subsubsection{Methodology}

The SWE estimation procedure developed for this application is based on a two-step procedure. In the first stage, the polarimetric decomposition proposed in (Pisciottano et al. 2011) is applied on fully polarimetric data acquired at $\mathrm{X}$ and C-band to separate volume and ground scattering contribution, then an entropy-based criterion is used to mask out vegetated areas. As second step, the decomposed VV and VH backscattered power components are used in the place of the respective backscattering coefficient as input for the CoReH2O inversion algorithm. For this, the original estimation procedure has been adapted to the single-frequency case (X- or C-band) considering only the modelling of the snowvolume backscattering. Some a priori information (from ground measurements) is also needed (e.g. snow density and temperature) as input for the estimation procedure.

The main advantage of using polarimetric decomposition for this application is the possibility to work with the only snow-volume scattering component. In this way, the SWE inversion is not depending on the ground layer conditions (dielectric constant, soil moisture, and roughness) anymore and the modelling of a ground scattering component becomes unnecessary. Consequently, the number of a-priori information needed for the inversion algorithm is considerably reduced.

\subsubsection{Polarimetric Decomposition for Snow-Covered Areas}

The polarimetric decomposition proposed in (Pisciottano et al. 2011) is used for the developed SWE retrieval procedure over open areas. It consists in a two-component decomposition, derived as adaptation of the model proposed in (Freeman 2007), originally developed for a volume of vegetation covering the ground. In the case of a snow cover scenario, the volume scattering component is attributable to the snow cover, acting as a volume of particles (snow grains), whereas the surface-like scattering contribution is due to the underlying ground. Both volume and ground component can be modelled by means of their respective coherency matrices.

The snow layer is assumed to be a volume of uniformly distributed and randomly oriented particles. An additional parameter is the shape factor $\rho$, ranging from $\rho=1 / 3$ for the case of dipoles to $\rho=1$ for spheres. Intermediate values of $\rho$ indicate spheroidal particles (Nghiem et al. 1992). Under this assumption, the volume coherency matrix can be expressed as (Hajnsek et al. 2007):

$$
\mathbf{T}_{v}=f_{v}\left[\begin{array}{ccc}
1+\rho & 0 & 0 \\
0 & 1-\rho & 0 \\
0 & 0 & 1-\rho
\end{array}\right]
$$

where $f_{v}$ corresponds to the intensity of the volume scattering component.

The surface scattering component is modelled according to the Bragg model and its coherency matrix results to be:

$$
\mathbf{T}_{s}=f_{s}\left[\begin{array}{ccc}
1 & \beta * & 0 \\
\beta & |\beta|^{2} & 0 \\
0 & 0 & 0
\end{array}\right]
$$

where $f_{s}$ is the intensity of the surface scattering component and $\beta$ is defined as:

$$
\beta=\frac{R_{h}-R_{v}}{R_{h}+R_{v}}
$$

with $R_{h}$ and $R_{v}$ representing the Bragg scattering coefficients for horizontally and vertically polarised wave, respectively.

The power contribution of the two components to the total backscattered power $P_{\text {tot }}$ can now be written as:

$$
\begin{gathered}
P_{s}=f_{s}\left(1+|\beta|^{2}\right) \\
P_{v}=f_{v}(3-\rho)
\end{gathered}
$$

corresponding to the trace of the associated coherency matrices. Using the transformation from coherency to covariance matrix (Hajnsek 2001) the VV and VH power contribution of the volume scattering component can be derived and written as:

$$
\begin{gathered}
P_{v}^{\mathrm{VV}}=f_{v} \\
P_{v}^{\mathrm{VH}}=f_{v} \frac{1-\rho}{2}
\end{gathered}
$$

The quantities $f_{v}$ and $\rho$ can be estimated from the coherency matrix of the real data as suggested in (Pisciottano et al. 2011).

\subsubsection{Snow Water Equivalent Retrieval Algorithm}

The original SWE inversion procedure proposed in (European Space Agency 2008) for the CoReH2O candidate mission is based on a dual frequency (X-and Ku-band) and dual polarisation approach and is developed for dry snow cover in open areas. The core of the procedure is a two-layer Dense Medium Radiative Transfer (DMRT) backscatter model. It relates the physical properties of the snow layer and the underlying ground to the SAR backscattering in the $\mathrm{VV}$ and $\mathrm{VH}$ polarisations. In particular, the snow volume is modelled as a layer of uniformly distributed spherical 
particles (snow grains), which have same size. Under this hypothesis, the volume backscatter contribution can be written as (Rott et al. 2008; Ulaby et al. 1984):

$$
\begin{aligned}
\sigma_{p q}^{v}\left(\vartheta_{t}\right)= & T_{p q}^{2}\left(\vartheta_{t}\right) \\
& \times\left[\frac{\omega_{p q}}{2}\left(1-\exp \left(-2 \frac{k_{e} \mathrm{SWE}}{\rho_{s} \cos \left(\vartheta_{t}\right)}\right)\right) \cos \left(\vartheta_{t}\right)\right]
\end{aligned}
$$

where $T_{p q}$ is the transmission coefficient at the air-snow interface; $p$ and $q$ the transmitted and received polarisation, respectively; and $\vartheta_{t}$ the transmitted angle through the snowpack. The snow parameters involved are the density $\rho_{s}$, the extinction coefficient $k_{e}$, the scattering albedo $\omega$, and the SWE.

The entire estimation algorithm can be split in two steps. First, VV and VH backscatter coefficients are simulated using the DMRT model, together with a set of a priori information and initialisation values of the parameters to estimate: SWE and grain size. Successively, a constrained optimisation method is applied pixel by pixel to iteratively match the simulated $\mathrm{X}$ - and Ku-band VV/VH backscatter coefficients to the measured values. The input values of SWE and grain size ensuring the reached optimum condition are finally assumed as estimates.

As already mentioned, this procedure is strongly dependent on the required a priori information about the ground and snowpack conditions. This kind of information are usually obtained through in situ measurements which are rather expensive, time-consuming, and can be conducted only on very small scale. Consequently, the dependency on a priori information represents a strong limitation when deriving SWE maps (and not single-point values) over a certain area.

In this sense, the modified SWE inversion procedure based on polarimetric decomposition results to be much more robust since the dependency on most of the a priori information is eliminated. First, the $\mathrm{CoReH} 2 \mathrm{O}$ algorithm has been adapted for a single-frequency case (X- or C-band). Then, the capability of the polarimetric decomposition to isolate the snow volume scattering component allows to focus the DMRT modelling on the only volume component. In fact, assuming that the volume backscattering is uncorrelated to the underlying ground layer (no second order scattering considered), there is no need to know soil conditions. This represents a significant simplification of the entire procedure since the ground contribution strongly influences the total backscattering. In addition, the sensitivity analysis of the CoReH2O DMRT model to the snow properties performed in (Pisciottano et al. 2011) showed that the backscattering contribution from the snow layer is mainly influenced by SWE and grain size, and only slightly dependent on other parameters, like snow temperature and density. This means that the latter two quantities need to be known for a rigorous SWE inversion, whereas a slightly rougher estimate can be obtained by assuming fixed values of snow temperature and density over the processed SAR scene. The scheme in Fig. 4.6 shows the working flow-line of the proposed SWE estimation procedure. The final products are SWE maps with a spatial resolution of about $20 \times 20 \mathrm{~m}$ in the case of TerraSAR-X data and $40 \times 40 \mathrm{~m}$ for RADARSAT- 2 .

\subsubsection{Experimental Results}

Test sites and corresponding radar and validation data sets selected for the generation of showcases on snow water equivalent retrieval are summarised in Table 4.3 and further described in the Appendix.

The SWE estimation procedure described before has been applied over different subsets of the available TerraSAR-X and RADARSAT- 2 dataset. A validation could be carried out only over the small areas where the ground measurements took place. For brevity, the focus is on test site of Sodankylae. In particular, the results shown in the following are obtained in correspondence of the Intensive Observation
Fig. 4.6 Scheme of the SWE estimation procedure based on polarimetric decomposition and modified $\mathrm{CoReH} 2 \mathrm{O}$ algorithm




Table 4.3 Test sites and corresponding radar and validation data selected for the generation of showcases on snow water equivalent retrieval

\begin{tabular}{l|l|l}
\hline Application/product & Test site - Radar data & Reference data \\
\hline \multirow{2}{*}{$\begin{array}{l}\text { Snow water equivalent } \\
\text { retrieval }\end{array}$} & Sodankylae, Finland & $\begin{array}{l}\text { Ground measurements (CASIX } \\
\text { experiment) }\end{array}$ \\
\cline { 2 - 3 } & $\begin{array}{l}\text { 3 TerraSAR-X quad-pol scenes (2010), 8 RADARSAT-2 quad-pol scenes } \\
(2011-2012)\end{array}$ & \\
\cline { 2 - 3 } & $\begin{array}{l}\text { Churchill, Canada } \\
\text { 3 TerraSAR-X quad-pol scenes (2010) 5 RADARSAT-2 quad-pol scenes } \\
(2011-12)\end{array}$ & \\
\hline
\end{tabular}

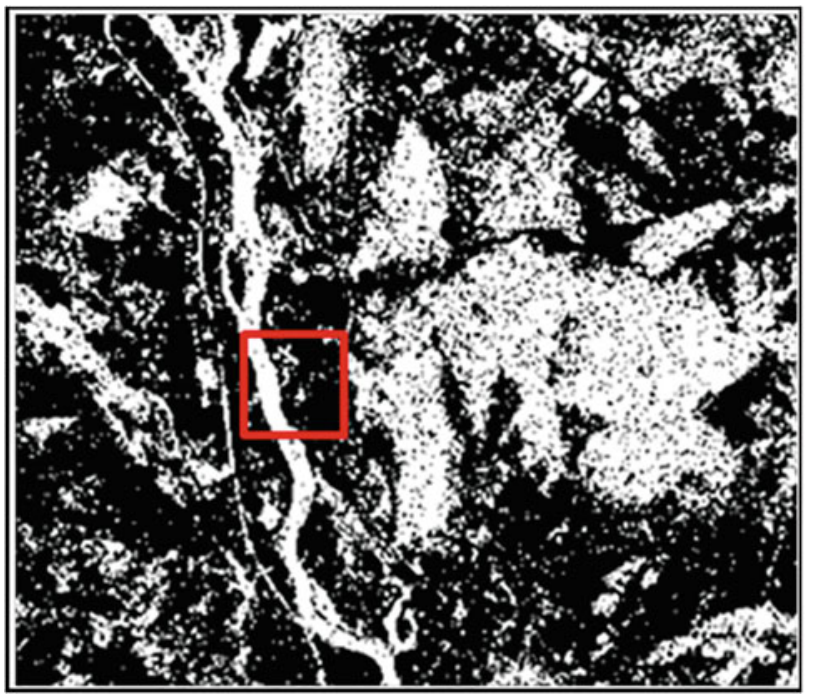

Fig. 4.7 The image on the left shows the entropy-based mask for open areas obtained from the TerraSAR-X acquisition of the 11.04.2010 over Sodankylae. The red box indicates the subset including the IOA where a

Area (IOA), where continuous SWE measurements are available for the same period of the SAR acquisitions.

The three TerraSAR-X acquisitions available for this test site were acquired on the 11th and 22nd of April and the 3rd of May 2010. In these dates, point measurements of SWE in the IOA reported values of $205 \mathrm{~mm}, 191 \mathrm{~mm}$, and $164 \mathrm{~mm}$, respectively. The corresponding retrieved values obtained from the inversion procedure, using snow density and temperature measurements as a priori information, are shown in Fig. 4.7, where a validation is also performed by comparison with the respective measured values of SWE. As clearly shown in Fig. 4.8, for the acquisition of April, the SWE inversion performs very well; estimated values of $211 \mathrm{~mm}$ and $193 \mathrm{~mm}$ correspond to measured values of $205 \mathrm{~mm}$ and $191 \mathrm{~mm}$, respectively. These results definitely satisfy the accuracy requirement established for the $\mathrm{CoReH} 2 \mathrm{O}$ mission. For the case of May, the worse performance can be due to the raising of air temperature reported in the ground measurements for that period. This may have led to a change in the snow-pack structure, moving away from the validity hypothesis of the used DMRT model. For the case of RADARSAT-2, preliminary results (see Fig. 4.9) seem to confirm the conclusions of (Bernier and Fortin 1998) since

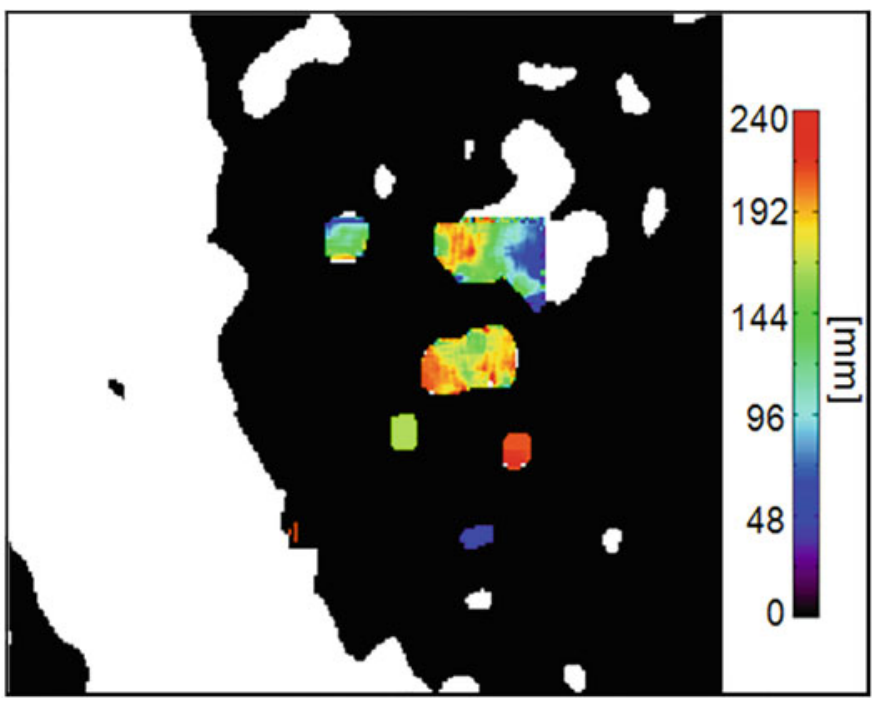

demonstration of SWE estimation has been performed (image on the right). SWE values are retrieved over a $60 \times 60$ pixels subset and range from $0 \mathrm{~mm}$ (black) to $240 \mathrm{~mm}$ (red)

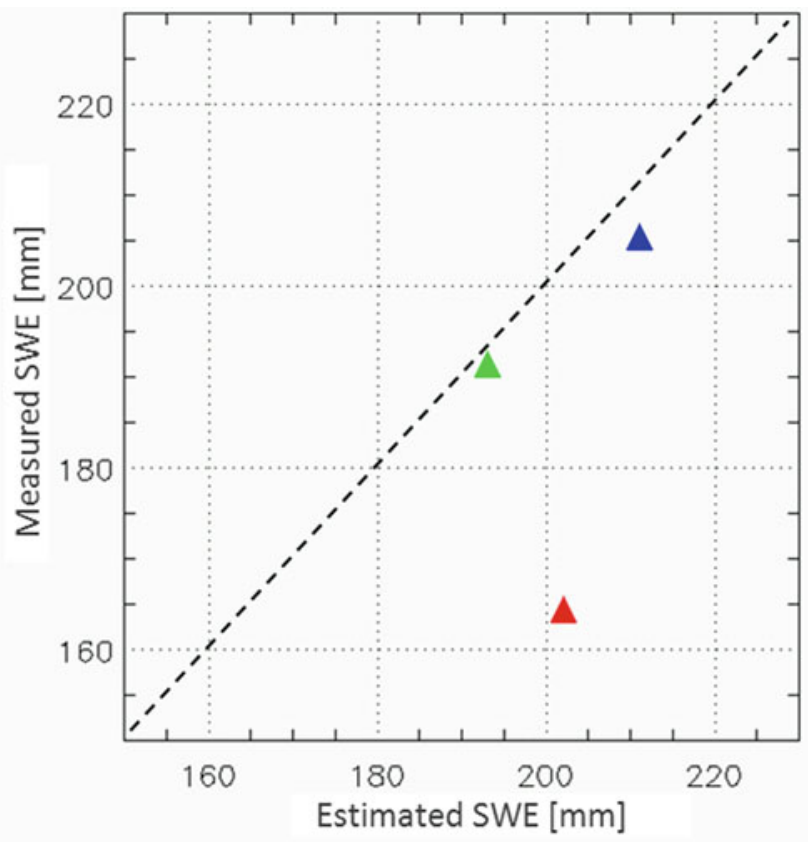

Fig. 4.8 Validation of estimated SWE over the IOA of the Sodankylae test site using the three TerraSAR-X acquisitions. Blue, green, and red symbols are referred to the dates of 11-04-2010, 22-04-2010 and 03-052010, respectively 


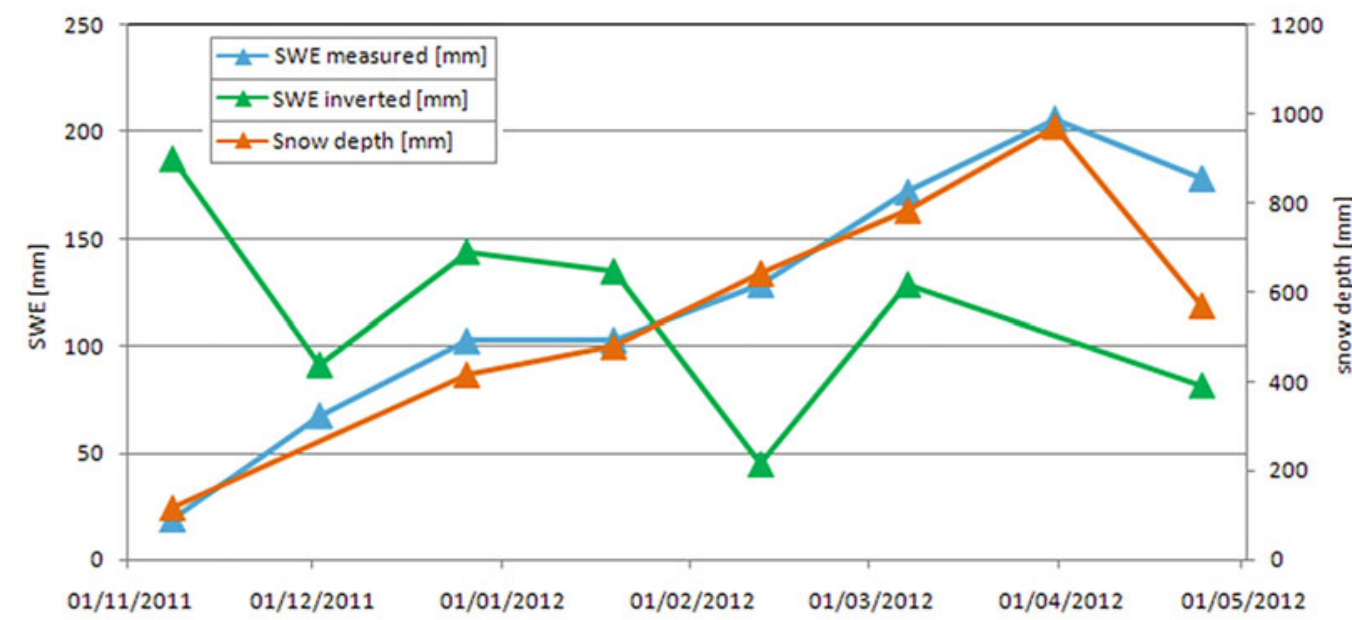

Fig. 4.9 Time series of measured SWE (blue), snow depth (orange), and inverted SWE (green) using RADARSAT-2 data for the Sodankylae IOA test site

almost no sensitivity can be observed along time in presence of the shallow snow cover (SWE always lower than $20 \mathrm{~cm}$ ) reported for Sodankylae.

\subsubsection{Comparison with Single/Dual Polarisation Data}

Some comparisons have been carried out between the employed methodology, based on fully polarimetric data, and the original $\mathrm{CoReH} 2 \mathrm{O}$ dual polarimetric retrieval procedure. Preliminary results show that the procedure based on polarimetric decomposition is more robust than the dual-pol procedure, especially when tested over different ground conditions (bare soil, swamp). This is attributable to the capability of the polarimetric-decomposition to extract the volume scattering component quite efficiently over different kinds of ground, while the efficiency of DRTM model for the ground scattering proposed in the dual-pol approach is severely compromised when soil condition are not known (Pisciottano et al. 2011). Nevertheless, these results have to be confirmed by further investigations.

\subsubsection{Discussion on the Role of Polarimetry, on the Maturity of the Application and Conclusions}

The importance of polarimetry in this kind of applications is well established, as already discussed in the literature review. Single polarisation studies have shown a very limited potential and were mainly employed for snow cover mapping. The introduction of polarimetry, even if with a dual-pol configuration, allowed deeper investigations about the scattering mechanisms and their relative contributions to the total scattering. They also contributed significantly for the development of more detailed physical models. Nevertheless, as observed for the case of the CoReH2O SWE inversion, a dual polarisation approach requires a significant a priori knowledge to be able to estimate snow properties (e.g. SWE, grain size, etc.). The introduction of fully polarimetric data makes possible the development of decomposition techniques for snow cover scenarios and has the big potential to reduce (almost eliminate) the need of any a priori information about the investigated test site.

\subsection{Sea Ice Characterisation}

\subsubsection{Sea Ice Observation with Quad-Polarimetric SAR}

\subsubsection{Introduction, Motivation, and Literature Review}

The observation of sea ice is a major topic in remote sensing due to the difficulty of performing frequent in situ expeditions (Elachi and Van Zyl 2006; Gareth Rees 2006; Jackson and Apel 2004). Monitoring of sea ice is important for many environmental issues (Sandven et al. 2006). First of all, it is a sensitive climate indicator, and it plays an important role in global climate systems. It restricts the exchange of heat and chemical constituents between ocean and atmosphere acting as an insulator. Moreover, it influences the global climate system with effects related to its elevated 
albedo, reducing the amount of solar radiation absorbed at the Earth's surface. On the other hand, sea ice affects oceanic circulation directly by the rejection of salt to the underlying ocean during ice growth, which is responsible for deep water formation. Besides these, the possibility and safety of navigation in Polar Regions is severely influenced by the presence of sea ice.

Microwave sensors and synthetic aperture radar (SAR) are very valuable for monitoring sea ice since they can acquire information in absence of solar illumination (i.e. during Polar nights) and with almost any weather conditions (Franceschetti and Lanari 1999). Unfortunately, the description of the backscattering behaviour of sea ice is particularly challenging. For this reason, many scientists moved towards systems able to increase the amount of information acquired. In this context, polarimetry plays a key role, because it is able to enhance dramatically the discrimination capability of the observed target, solving many ambiguities revealed in single polarisation images (Cloude 2009; Lee and Pottier 2009; Van Zyl 2011). Specifically, sea ice could be modelled as a layered media showing several interfaces: air-snow, snowice, and (eventually) ice-water (Elachi and Van Zyl 2006; Jackson and Apel 2004; Drinkwater et al. 1992; Nghiem et al. 1995a, b; Ulaby et al. 1986b).

An introduction to polarimetry is provided in the first chapters of this book. In this section we only concentrate on the polarimetric models introduced to characterise sea ice. Several models were proposed to predict the polarimetric behaviour of sea ice (Nghiem et al. 1995a, b; Ulaby et al. 1986b; Carlström 1997; Tjuatja et al. 1992). A thorough description of them is outside the purpose of this Section.

\subsection{Polarimetric Models}

To understand the backscattering from ice, it is important to know the physical differences between different ice types. Here, only a very short inventory is reported and the reader is redirected to the World Meteorological Organization (WMO) Sea Ice Nomenclature document for further details. Following its formation, the ice can be defined new ice (frazil ice, grease ice, slush and shuga), nilas (below $10 \mathrm{~cm}$ thick), young ice (10-30 cm thick), first year ice $(30 \mathrm{~cm}$ to $2 \mathrm{~m}$ thick), and old or multi-year ice (that has survived at least one melting season). The floating structures are generally called floes (that can have extensions from few metres to several kilometres). Another structure commonly seen during ice formation is pancakes (generally smaller than $3 \mathrm{~m}$ ) that may present raised rims and draft. With deformed ice, it is designed ice that suffered deformations due to pressure or melting. Some classical structures are ridges and hummocks. Another interesting feature of sea ice areas are leads, which are openings (cracks) in the ice tens of metres large and up to several kilometres long. Each of the ice formations or features will have a characteristic scattering behaviour.
Sea ice is generally modelled as a multi-layer medium:

1. The first interface is between air and snow cover (Tjuatja et al. 1992; Beaven et al. 1995). The behaviour of this first layer is strongly dependent on the dielectric properties of the snow, which are dependent on factors as water content and temperature. If the dielectric constant is small enough (i.e. dry and cold conditions), this interface will not scatter much, and the snow will be transparent to the electromagnetic wave. It is important to keep in mind that in some conditions as during snow melting this layer can mask completely the underneath ice.

2. The second interface is snow-ice. The behaviour of this interface depends on the difference in dielectric constants between snow and ice (Nghiem et al. 1995a, b; Ulaby et al. 1986b). If the ice is highly saline, its dielectric constant is quite high, and the most of the backscattering will come from the surface. On the other hand, if the ice is less saline, the electromagnetic wave can penetrate, and a consistent volume scattering will be observed (Beaven et al. 1995). Another important factor in the balance of surface and volume scattering is the surface roughness. As a role of thumb, higher roughness (compared with the wavelength) will provide higher backscattering (Ulaby et al. 1986b). The Bragg model is generally exploited to characterise the surface scattering, but when the roughness is very large, an extended version of the model should be used (Cloude 2009).

3. Ice volume: Characterising the backscattering of the ice volume is particularly challenging due to the large differences showed by ice types (strongly depending on their formation process). From experiments and modelling, it appears that the backscattering mainly comes from brine inclusions which represent small discontinuities in the volume. Polarimetry is expected to be useful to acquire some insight on the typology of ice, since it is sensitive to particles anisotropy and orientation (Nghiem et al. 1995a, b; Ulaby et al. 1986b).

Besides a simple layered structure, ice generally presents a large variety of deformation features due to the action of sea and wind that compress and crack floes (Carlström 1997; Isleifson et al. 2009; Onstott et al. 1998). Ridges, hummocks, and areas with broken ice are generally (but not necessarily) bright in the SAR images. This makes possible, in some instances, the identification of floes edges (Dierking and Dall 2007). Polarimetry combined with heterogeneity analysis may play a role in detecting such features, since their polarimetric behaviour is expected to be different from the one of homogeneous floes.

Another feature observable under some circumstances is the frost flowers. They form in calm and windless conditions when the atmosphere temperature is much lower than the one 
of the ice (Isleifson et al. 2010). They may present a very large backscattering which may be eventually misinterpreted by some models.

\subsection{Validating Models and Experiments}

Many experiments were carried out in order to test the polarimetric models. Some of them consider laboratory conditions, where all the parameters are under control and can be accurately monitored. A famous series of experiments were the CORRELEX (Nghiem et al. 1995b; Beaven et al. 1995). Although in a lab it is possible to control accurately the experiment, there may be problems in replicating some of the characteristics of sea ice formations that are only achievable in the field. For instance, the mechanical effect of waves is central in ice formation. One experiment that tried to capture this characteristic is presented in Onstott et al. (1998).

Another way to test models is to use a scatterometer and collect data over actual sea ice (Nghiem et al. 1995b; Isleifson et al. 2009; Dierking 1999; Geldsetzer et al. 2007; Kern et al. 2006; Partington et al. 2010). Clearly this approach may lack control compared to a lab experiment, and it is generally limited to a reduced number of ice types; however, it is often preferred to lab experiments because it is able to picture more realistic scenarios.

\subsubsection{Methodology}

In this section the employed methodologies and polarimetric observables are briefly listed. Details about them can be found in the introductory chapters, here only the applicability to sea ice observation is examined.

\subsection{Co-polarisation Ratio}

This is defined as the averaged intensities of $\mathrm{VV}$ over $\mathrm{HH}$ polarisations. In the literature, many authors have used this observable (Geldsetzer et al. 2007; Kern et al. 2006; Drinkwater et al. 1990; Geldsetzer and Yackel 2009; Kwok et al. 1991) for several reasons. (1) To detect open water and leads: it is a useful discriminator between Bragg and volume scattering (Geldsetzer and Yackel 2009). A complication is when water in very calm conditions has a very low signal-tonoise ratio (SNR), which makes the two Co-Polarisations more similar. (2) To analyse volume scattering: due to particles anisotropy, it is sometimes observed that the volume can have HH power higher than VV (Geldsetzer et al. 2007). (3) Ice thickness: the balance of surface and volume scattering in sea ice is ruled by dielectric constant and roughness. When these two are high, the sea ice behaves more as a surface; otherwise a volume is observed (Kern et al. 2006). Interestingly, the dielectric constant is strongly dependent on the ice salinity, and the latter exhibits some dependency on ice thickness (thicker ice is less saline due to expulsion and washing up during melting seasons). Therefore, thicker ice should have a lower ratio, and several attempts were made to find a regression curve to extract thickness from this ratio (Kim et al. 2012; Wakabayashi et al. 2004).

\subsection{Cross-Polarisation Ratio (or Depolarisation Ratio)}

This is the ratio between a cross-pol and a co-pol channel (Kim et al. 2012; Thomsen et al. 1998). This can be extended using the sum of cross-polarisations over the sum of co-polarisations (Geldsetzer et al. 2007). It is mainly employed to:

1. Detect open water: water is expected to have low CrossPolarisation backscattering.

2. Ice thickness: for similar reasoning like the Co-Polarisations Ratio (Kim et al. 2012).

\subsection{Co-polarisation Coherence}

Many authors exploited the coherence between the two co-polarisations $\gamma_{C o}$ for sea ice monitoring (Nghiem et al. 1995b; Isleifson et al. 2009; Geldsetzer et al. 2007; Drinkwater et al. 1990; Kwok et al. 1991; Israelsson and Askne 1991), for the following reason. Analysing surface and volume scattering, both magnitude and phase provide information regarding the scattering process. For instance, a zero phase difference with small standard deviation is an indicator of surface scattering. Regarding volume scattering, isotropic (spherical or randomly oriented) particles provide again zero phase difference but with a standard deviation generally larger compared to surfaces. Finally, different phase behaviours can be observed depending on the particles anisotropy and orientation (Nghiem et al. 1995a, b; Ulaby et al. 1986b).

\subsection{Circular Polarisation Coherence}

This observable is very sensitive to: (1) surface roughness (Wakabayashi et al. 2004), using the magnitude; (2) orientation of the observed targets (Lee et al. 2000, 2002), using the phase. In the case of ice floes, a large scale surface variation can introduce a large phase standard deviation (Wakabayashi et al. 2004). Moreover, target (i.e. particles or surface features) orientation can be analysed and it can be used to solve misclassification with volume scattering.

\subsection{Cross-Polarisation Coherence}

In some situations (especially in melting conditions), the cross-polarisation backscattering from ice is particularly low; consequently, the signal-to-noise ratio, SNR, (defined as the ratio between averaged intensity of signal over intensity of noise) is low. This coherence can be used to check the reliability of cross-channel measurements over dark areas. 


\subsection{Cloude-Pottier Decomposition}

Several examples can be found where the Cloude-Pottier decomposition is employed for sea ice observation, and they are mainly related to (1) classification and (2) features extraction (Wakabayashi et al. 2004; Scheuchl et al. 2002, 2003a; Wesche and Dierking 2012).

\subsection{Noise Estimation/Mitigation}

Every time a coherence is estimated, it is important to understand whether it represents a physical decorrelation effect or not. Quad-polarimetry allows a very powerful methodology for estimating the value of the noise floor (Cloude 2009). Thermal noise decorrelation can be easily estimated based on the SNR of the specific channels (e.g. the two co-polarisations). Also some noise mitigation procedure can be exploited (Cloude 2009).

\subsubsection{Experimental Results}

Test sites and corresponding radar and validation data sets selected for the generation of showcases on sea ice observation are summarised in Table 4.4 and further described in the Appendix.

In this Section the results obtained using polarimetric observables are presented. For the sake of brevity, only few observables will be displayed. Figure 4.10 presents the Storfjord dataset, while Fig. 4.11 shows the Barents Sea dataset. In all the images, the horizontal axis is azimuth and the vertical is range (near range at the bottom and far range at the top of the image). The average (filtering) used considers a boxcar of $7 \times 28$ pixels. Such window should provide an equivalent number of looks of around 86. Moreover, only for visualisation purposes, the images consider the multi-look of 4 pixels in azimuth, which makes the pixels on the ground

Table 4.4 Test sites and corresponding radar and validation data selected for the generation of showcases on sea ice observation

\begin{tabular}{l|l|l}
\hline Application/product & Test site - Radar data & Reference data \\
\hline \multirow{2}{*}{ Sea ice observation } & Fram strait, Storfjord, Barents Sea (Svalbard) & No ground measurement available \\
\cline { 2 - 2 } & E-SAR L-band & \\
\hline
\end{tabular}
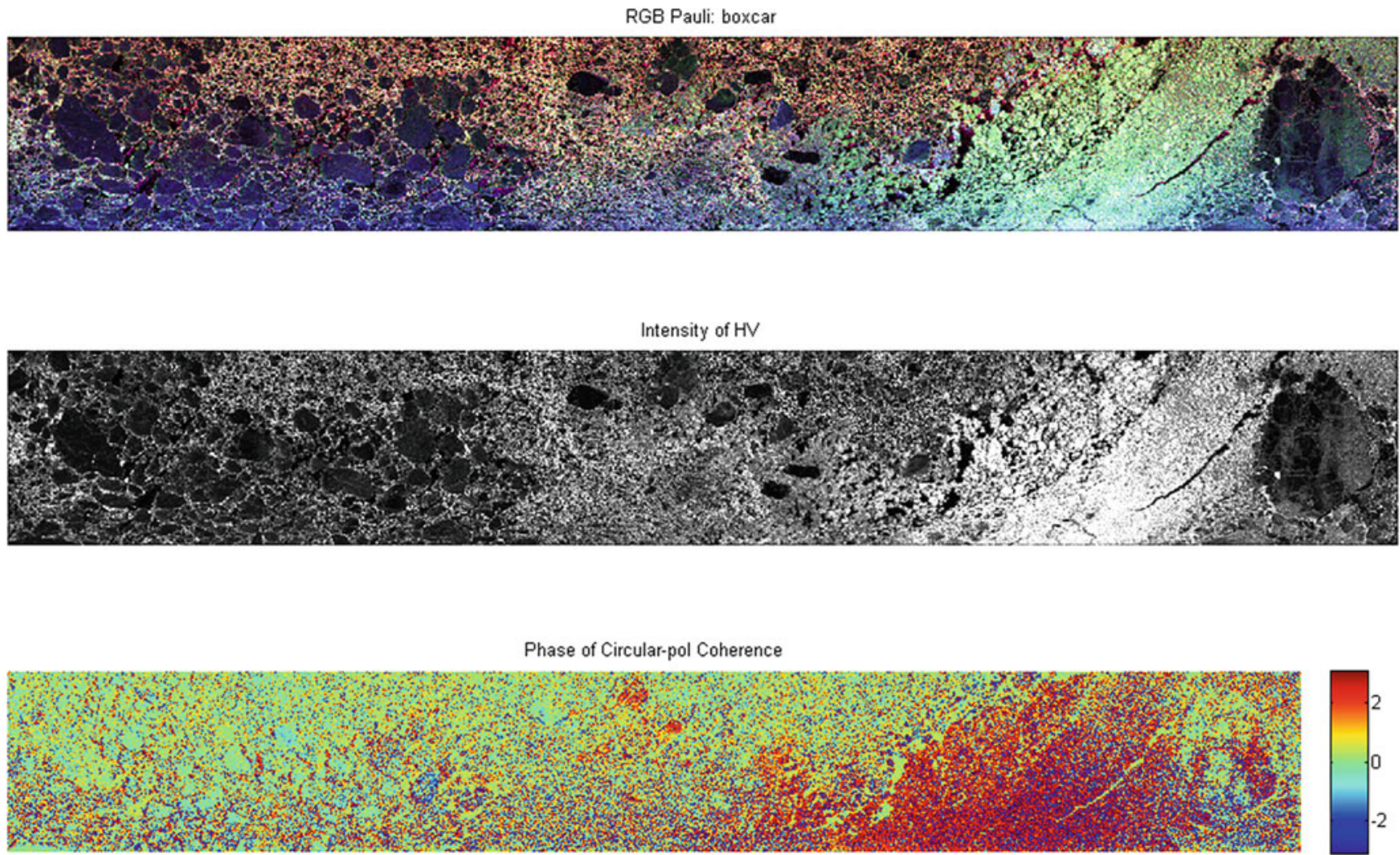

Fig. 4.10 Polarimetric analysis of L-band ICESAR data: Storfjord (16.03.2007). RGB Pauli composite image (Red, $|\mathrm{HH}-\mathrm{VV}|^{2}$; Green, $|2 \mathrm{HV}|^{2}$; Blue, $\mid \mathrm{HH}+\mathrm{VVI}^{2}$ ); intensity of cross-polarisation; phase of circular-polarisations coherence 


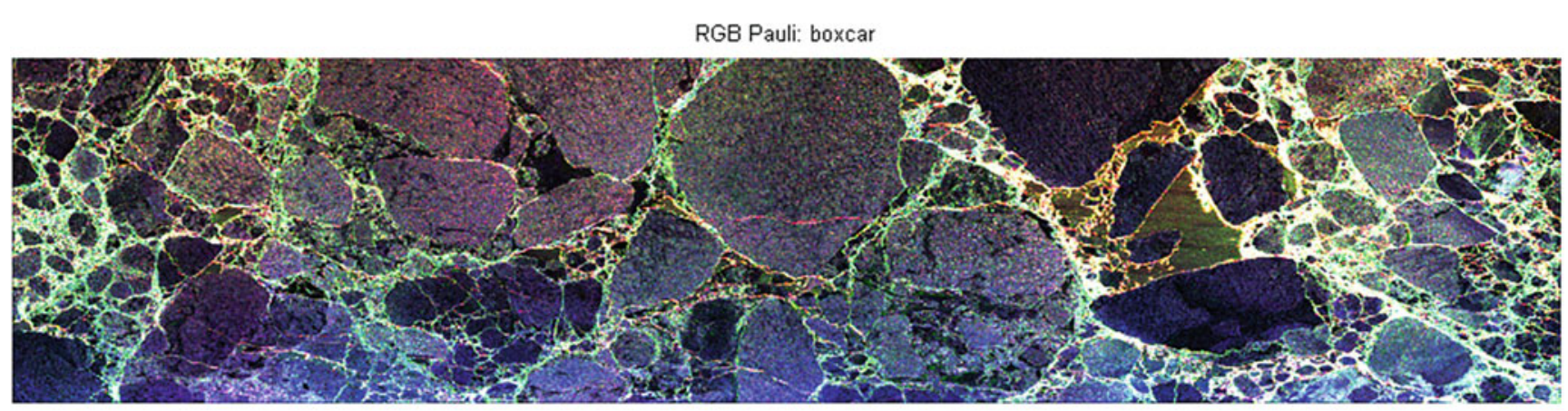

CoPolarisations Ratio

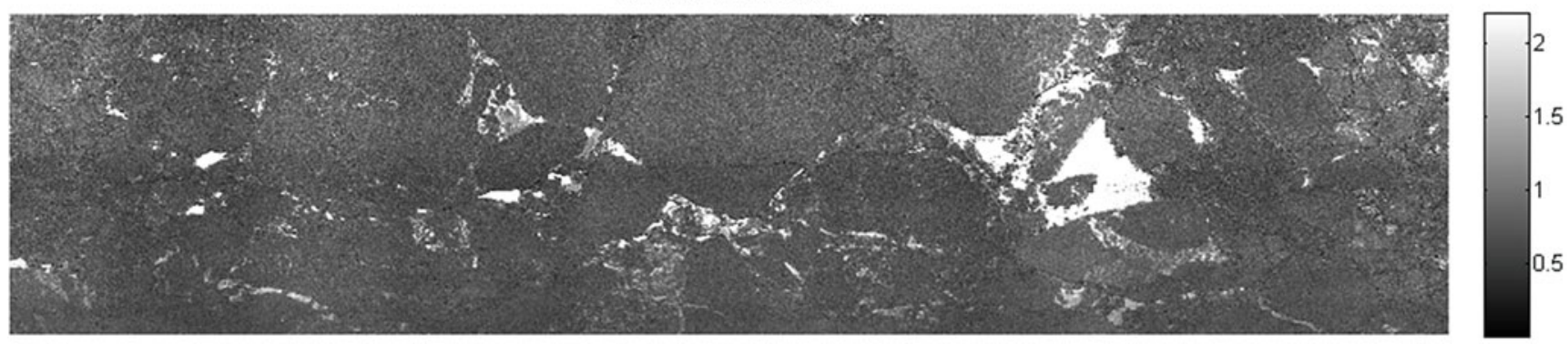

Magnitude of $\mathrm{CoP}$ ol coherence
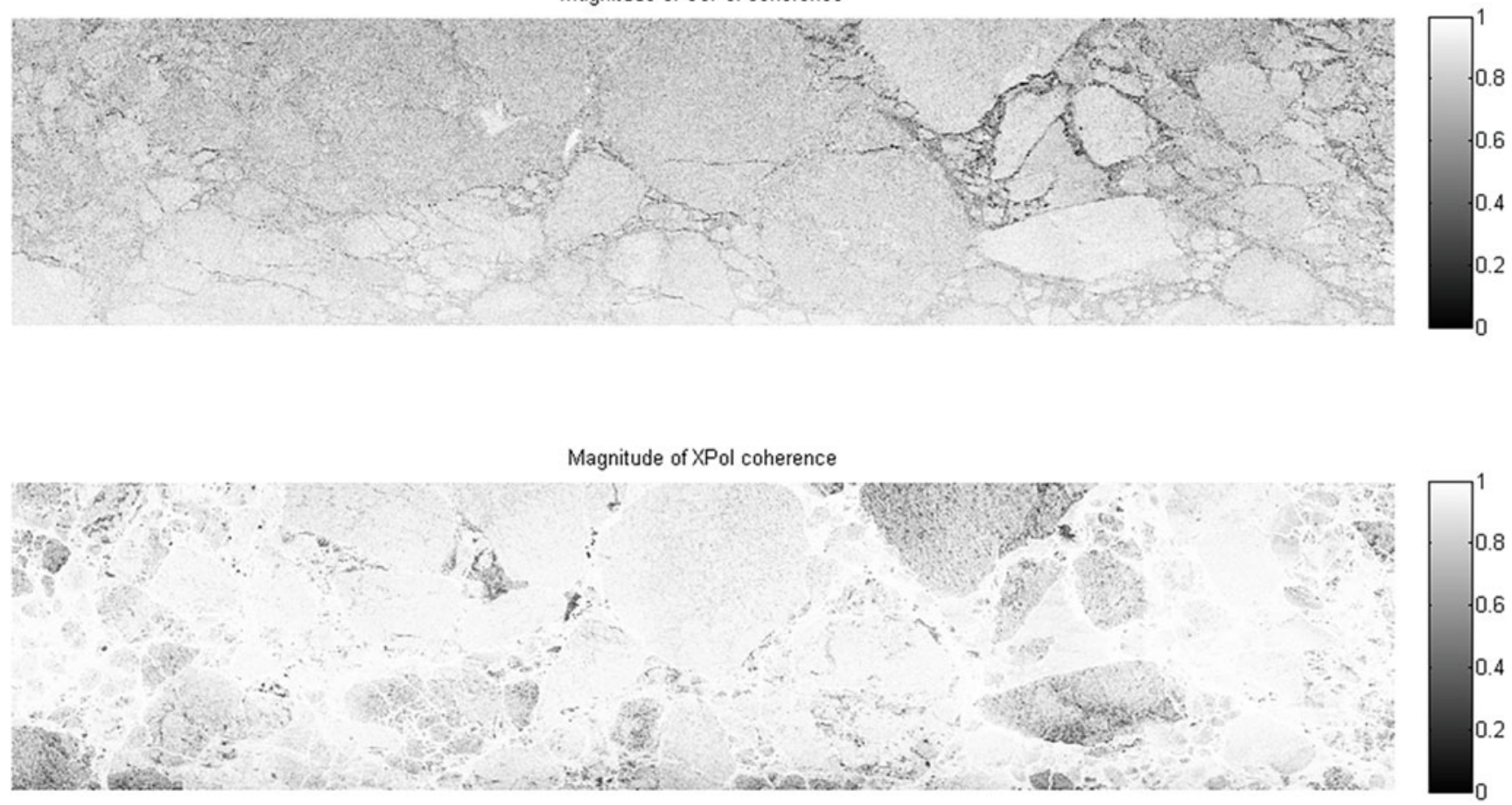

Fig. 4.11 Polarimetric analysis of L-band ICESAR data: Barents Sea (18.03.2007). RGB Pauli composite image (Red, $\mid \mathrm{HH}-\mathrm{VVI}^{2}$; Green, $|2 \mathrm{HV}|^{2}$; Blue, $\mid \mathrm{HH}+\mathrm{VVI}^{2}$ ); co-polarisations ratio; magnitude of co-polarisations coherence; magnitude of cross-polarisations coherence 
more squared (please note, this depends on the range location in the image).

Results can be interpreted as follows:

1. Pauli RGB: It can be noticed that the simple visualisation of the Pauli RGB image can help significantly to distinguish between different sea ice types. Interestingly, it appears that the colour of the images is bluer in the near range (bottom: around $26^{\circ}$ of incidence angle) than in far range (top: about $65^{\circ}$ of incidence angle). This is in line with many models that predict a stronger surface contribution for small incidence angles and a larger volume contribution for larger incidence angles (Nghiem et al. 1995b; Carlström 1997; Tjuatja et al. 1992).

2. Phase of circular-polarisation: in Fig. 4.10, a green (i.e. HV) bright area is visible. Strong backscattering in the cross-channel is often associated with volume scattering (e.g. multiyear ice, MYI). However there is no MYI in the scene. Only by analysing this phase it is possible to understand that the strong cross return is due to orientation effects (i.e. it is not MYI). The reason of such orientation is not completely known; nevertheless the correction allowed solving this ambiguity.

3. Co-polarisation ratio: This observable is very powerful to highlight areas of open water (Geldsetzer and Yackel 2009). In Fig. 4.11, the bright areas correspond to open water (this was validated with a photograph captured during the flight pass).

4. Co-polarisation coherence: This is used to discriminate between different kind of scattering mechanisms and volume types. Figure 4.11 represents an example where the magnitude of this observable can be used to discriminate between floes. Additionally, some studies described correlation between this observable and ice thickness (Nghiem et al. 1995b).

5. Cross-polarisations coherence: From Fig. 4.11, it can be seen that some floes present a low value (i.e. low SNR), and therefore care has to be given when the crosspolarisation is used to retrieve parameters over such areas.

\subsubsection{Discussion on the Role of Polarimetry, on the Maturity of the Application and Conclusions}

Few conclusions could be drawn on the benefits of using polarimetric data for sea ice observation.

1. Higher discrimination: The use of four images instead of one enhances the capability to characterise the scattering process. For instance, the co-polarisation ratio can be used to detect open water, and the co-polarisations coherence tells about the scattering mechanism. If our interest is focused on detecting ice features as ridges or hummocks, then the depolarisation ratio or the Cloude-Pottier decomposition can be useful.

2. Avoiding misclassification (correction for orientation angle): Another powerful methodology only possible with quad-pol data is the correction for orientations of observed targets. The latter can produce misclassification (in this case with multi-year ice).

3. Noise estimation/mitigation: With quad-pol data, it is possible to estimate locally the noise floor and understand where the measurements are less reliable due to noise (and therefore they should not be used for quantitative analysis).

As a final remark, from the literature it seems that polarisation has a valuable role in sea ice observation (even if just with dual-polarimetric data). It is generally quite agreed that at least a dual-polarimetric mode is necessary in order to understand the behaviour of different kinds of sea ice. In some instances, the refrain in exploiting polarimetric modes is the impossibility to acquire very large swaths (as ScanSAR images) that in many sea ice applications are needed to cover vast areas in short time. Fortunately, many of the new generations of satellites will be able to acquire polarimetric data with wide swaths.

\subsubsection{Sea Ice Segmentation and Classification from Fully Polarimetric SAR Imaging}

\subsubsection{Introduction, Motivation and Literature Review}

SAR images of sea ice reveal large variability in appearance as function of imaging geometry (incidence angle, polarisation, frequency), physical properties (surface roughness, ice type, and other surface properties), and meteorological conditions. Wave propagation effects, such as attenuation, emission, and scattering, are strongly affected by physical properties like salinity, temperature, snow cover, wetness, volume structure, and surface roughness (Kong 1986). As a result, the physical structure of sea ice leads to radar signatures that may enable image segmentation and ice type classification.

Sea ice is in general divided into two major categories, first-year ice (FY) and multi-year ice (MY). MY ice has survived at least one summer melt and is discriminated from FY-ice on the basis of properties such as deformation (roughness, surface topography), thickness, salinity, and snow cover (Nghiem et al. 1995a). The extent of deformation is exploited when trying to discriminate ice types. The most commonly referred sea ice types are level ice, rafted ice, ridged ice, rubble fields, and hummocked ice. Level ice is ice with a relatively flat surface, which has not been deformed 
to any extent. Rafted ice arises when ice sheets collide and override one another; it occurs usually on new and FY-ice. Pressure processes cause the ice to pile up both above and below the surface. A ridge is the result of such processes and can be described as a long line of piled up, cracked ice. Repeated ridging causes rubble fields. Leads are open water channels in areas of predominantly sea ice. In addition, there exist several ice types representing young and thin sea ice.

The emergence of dual- and fully polarimetric spaceborne SAR systems gives prospects for enhancement of the amount of information about sea ice that can be obtained from satellite-borne sensors.

The goal of this note is to present an example of the improvements gained in characterisation of sea ice by utilising polarimetric observations instead of just singlepolarisation SARs. We will here focus on how polarimetry may improve segmentation and classification.

From previous studies of multi-polarisation measurements of sea ice, the knowledge status can currently be summarised as follows:

- Polarimetry is promising for the identification of the early stages of new (thin) ice formation and the discrimination of ice and open water (Dierking et al. 2003).

- The role of phase in polarimetric classification is unclear.

- The optimal frequency for polarimetric classification remains unclear and varies with application and region (Dierking et al. 2004). Overall, L-band appears to be more effective for full polarimetric ice classification than C-band.

- Multi-frequency is superior to single-frequency polarimetry. This would require improved methods for data integration and data fusion processing.

Full polarimetric SAR observations allow for the decomposition of radar signals into the contributions from the various scattering mechanisms. Even if it is generally known that scattering from sea ice is dominated by surface scattering, the backscattered signals may include contributions from several mechanisms. The relative contributions of rough surface scattering, specular reflections, volume scattering, and multiple scattering processes depend on thickness, degree of deformation, size of deformed structures, amount of snow on the ice, salinity, and compactness of the ice fragments (Dierking et al. 1997).

Several polarimetric parameters have been evaluated for first year sea ice discrimination in C-band RADARSAT-
2 data in (Gill and Yackel 2012), and the authors obtained a classification accuracy greater than $90 \%$. Extracting polarimetric information from sea ice scenes was the main subject of (Eltoft et al. 2012), and it was noted that the multitude of decomposition parameters are yet to be fully evaluated for sea ice discrimination.

\subsubsection{Methodology}

The workflow for retrieval of sea ice information undertaken in this Section includes two major steps. The first step is an unsupervised segmentation of the image, which subdivides it into a given number of segments based on variations in statistical and polarimetric properties. This step is followed by a polarimetric analysis, where the objective is to infer the polarimetric properties of each image segment. These properties may be interpreted in terms of physical characteristics, which may help label the segments into ice types.

The PolSAR image is segmented using a mixture of Gaussian models for the global probability density function (pdf). We assume reciprocity, and the segmentation algorithm uses the following 6 parameters generated from the general $(3 \times 3)$ C-matrix, as described in (Doulgeris and Eltoft 2010; Doulgeris 2013). These 6 parameters are geometric brightness, co-polarisation ratio, cross-polarisation ratio, co-polarisation, correlation magnitude, and co-polarisation correlation angle. The six features are nonlinearly transformed such that the marginal pdfs have a Gaussian-like appearance at the peaks. We then model the global pdf as a multivariate Gaussian mixture distribution and segment the image into a given number of unlabeled segments using the expectation maximisation algorithm, as described in (Doulgeris and Eltoft 2010). The proper number of classes is currently manually estimated based on optical images, the Pauli image, the sea ice observation log, and the segmentation results obtained with different number of classes.

\subsubsection{Experimental Results}

Test sites and corresponding radar and validation data sets selected for the generation of showcases on sea ice segmentation and classification are summarised in Table 4.5.

The smoothed, geocoded segmentation result is shown in Fig. 4.12. The image has been segmented into five classes. Sea ice experts interpreted the segmentation result aided by thickness measurements, optical photos, and the Pauli image. According to their interpretation, the yellow class is thin ice or open water; the red class is young, thin first year ice with

Table 4.5 Test sites and corresponding radar and validation data selected for the generation of showcases on sea ice segmentation and classification

\begin{tabular}{l|l|l}
\hline Application/product & Test site - Radar data & Reference data \\
\hline $\begin{array}{l}\text { Sea ice segmentation and } \\
\text { classification }\end{array}$ & $\begin{array}{l}\text { Arctic Sea, north of } \\
\text { Svalbard }\end{array}$ & $\begin{array}{l}\text { Ice thickness measurements (EM-bird), optical photos, roughness } \\
\text { measurements }\end{array}$ \\
\cline { 2 - 2 } & $\begin{array}{l}\text { RADARSAT-2, April } \\
2012\end{array}$ & \\
\hline
\end{tabular}




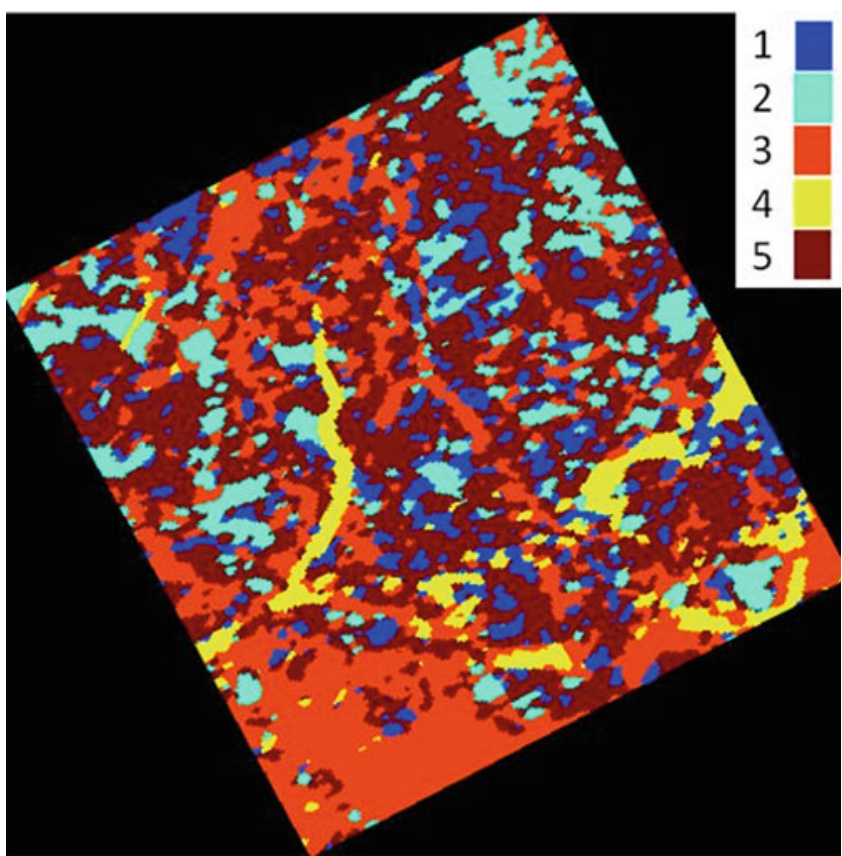

Fig. 4.12 Image segmented by the automated segmentation algorithm into five classes snow cover and some deformation; the blue, brown, and cyan classes are various stages of first year ice.

Figure 4.13 displays the thickness estimates along the helicopter track. As can be noted, the thickness varies between 0 and 6-7 m. Below the thickness curve, we have plotted the image segments along the flight track. By comparing the thickness and the coloured segments, we can conclude that the yellow class certainly corresponds to thin, new frozen ice, or open leads. We also see strong fluctuations in thickness in some classes, indicating deformed ice. We note that the cyan class seems to have the least thickness variations, indicating that this is a smooth ice type. This observation is in agreement with the fact that this class has very low backscatter. However, this class consists of relatively thick ice, around $1.5 \mathrm{~m}$ according to the EM-bird estimates.

\subsubsection{Comparison with Single/Dual Polarisation Data}

As illustrated in Fig. 4.14, radar polarimetry will in general increase the dimension of the feature space and enable retrieval of more information from a scene. Whereas single polarisation SAR images basically allow for image

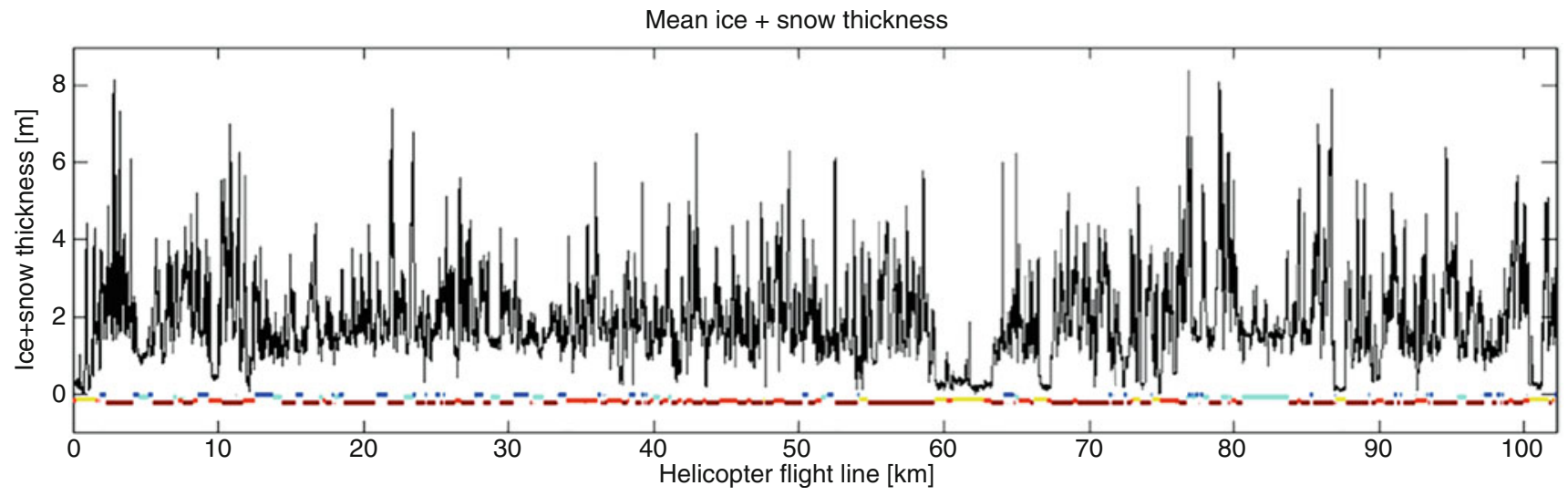

Fig. 4.13 Thickness estimates from EM-bird measurements. The colour segments at the bottom corresponds to the segments along the flight track

Fig. 4.14 The added feature space dimension by radar polarimetry

\section{Single polarization}

$$
\begin{aligned}
s_{l} & =\operatorname{Re}\left\{s_{l}\right\}+j \operatorname{Im}\left\{s_{l}\right\} \\
I_{l} & =\left|s_{l}\right|^{2} \\
I_{L} & =\frac{1}{L} \sum_{i=1}^{L} s_{i}
\end{aligned}
$$

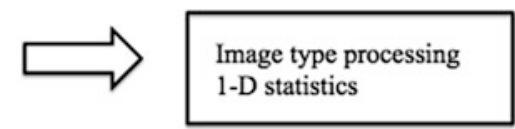

Multiple polarizations

$\mathbf{S}=\left[s_{h h}, s_{h v}, s_{v h}, s_{v v}\right]^{t}$
$C=\frac{1}{L} \sum_{i=1}^{L} \mathbf{s}_{i} \mathbf{s}_{i}^{*}$$\longrightarrow$\begin{tabular}{l|}
$\begin{array}{l}\text { Multidimensional } \\
\text { statistical analysis }\end{array}$ \\
\hline
\end{tabular}


processing type analysis, polarimetry will allow for both polarimetric analysis, to infer scattering information, as well as the use of advanced multivariate statistical methods. With respect of the current application showcase, we note that a single polarisation image will be restricted to only two parameters, the multi-looked intensity and a measure of non-Gaussianity. Polarimetry allows for much more, and it is a subject for future research to optimise the feature selection. From our experience, polarimetry will result in more detailed segmentation.

\subsubsection{Discussion on the Role of Polarisation, on the Maturity of the Application and Conclusions}

This Section has presented the result of segmenting a RADARSAT-2 PolSAR scene of Arctic sea ice, collected north of Svalbard in the Spring 2011. The scene shows various stages of first year ice, plus leads, some open, and some refrozen. The data set also comprised in situ data such as EM-bird thickness measurements, and optical photos along the helicopter tracks covered by the SAR image.

The analysis shows that the feature set consisting of six statistical and polarimetric parameters has discrimination power and enables segmentation of this sea ice scene into five proper segments. Some of these can be identified as distinct ice types. The added information associated with full polarimetry allows for a more detailed segmentation of the scene, as well as providing scattering mechanism information, which may subsequently help labelling the segments into ice types.

\subsubsection{Antarctic Sea Ice Thickness Using Sea Ice Surface Measurements and TerraSAR-X Data}

\subsubsection{Introduction, Motivation and Literature Review}

Sea ice thickness data is critical to the long-term assessment of climate change in the Polar Regions. The validation of sea ice remote sensing products in Antarctica has been complicated by remote location, limited extent, and infrequency of direct measurements. Estimates of sea ice thickness are particularly important in the Antarctic due to the limited opportunities for direct physical measurements, even when access is available.

Research objectives described in this Section are:

- Obtain spatially and temporally coincident ice measurements and TerraSAR-X (TSX) satellite measurements of Antarctic sea ice floes in the Bellingshausen Sea, an area that has undergone significant change.
- Examine polarimetric descriptors derived from TSX related to sea ice and snow characteristics for sea ice floes.

- Assess statistical relationships between surface elevation, snow depth, freeboard, ice thickness, and roughness with the ultimate goal of classifying sea ice types and calculating sea ice thickness from active radar returns.

This research benefited from direct collaboration with the British Antarctic Survey (BAS), Scottish Association of Marine Science (SAMS), and other international participants in obtaining in situ sea ice measurements during the IceBell field campaign in November 2010. The results of these efforts were used to derive sea ice and snow cover thickness relationships in the Antarctic which ultimately could improve satellite remote sensing products, allowing improved long term monitoring of the ice mass balance in the Antarctic sea ice zone.

Both passive and active microwave remote sensing have provided useful information on the extent and area of sea ice in both Polar Regions and their trends of change over approximately 30 years. Techniques for monitoring ice thickness from space have used altimetry measurements from lasers and the buoyancy of the snow and ice relative to local sea level reference (Zwally et al. 2008; Yi et al. 2011; Kurtz et al. 2009; Kurtz and Markus 2012). An alternate approach uses empirical relationships developed from in situ field data to derive ice thickness from snow freeboard (Xie et al. 2011).

Previous studies of the potential of polarimetric SAR data for sea ice monitoring and characterisation have concentrated on thin-ice due to limited data available (Scheuchl et al. 2004) which resulted in part from a lack of coincident surface measurements with SAR acquisitions. Attempts to obtain thin-ice thickness from airborne radar imagery have been made using full polarimetric data acquired by JPL's AIRSAR (Nghiem et al. 1995a; Rignot and Van Zyl 1992; Rignot and Drinkwater 1994; Kwok et al. 1995; Winebrenner et al. 1995), Danish EMISAR (Thomsen et al. 1998; Dierking et al. 2004; Skriver and Pedersen 1995), Canadian Convair580 SAR (Livingstone et al. 1996; Scheuchl et al. 2003b), German HELISCAT (Kern et al. 2006), and Japanese PiSAR (Wakabayashi et al. 2004; Matsuoka et al. 2002; Nakamura et al. 2005). Fully polarimetric spaceborne SAR data were first acquired over sea ice in 1994 by the SIR-C mission, with first results reported by Eriksson et al. (1998). Other results based on high-resolution polarimetric data were reported using ALOS-PALSAR (e.g. Wakabayashi and Sakai 2010), RADARSAT-2 (e.g. Kim et al. 2012), and TerraSAR-X (e.g. Kim et al. 2012; Busche et al. 2009).

Scheuchl et al. (2005) indicate that swath widths for fully polarimetric modes are limited and will not provide sufficient coverage for operational sea ice monitoring. This research allowed for multiple acquisitions of X-band dual-polarisation 
SAR for tracking distinct ice floes, in conditions of rapid drift, typically over $100 \mathrm{~m} / \mathrm{h}$, with $80 \%$ success. The proposed ice-thickness method improved on existing techniques showing high potential in operational sea ice monitoring.

\subsubsection{Methodology}

Radar backscatters are affected by thick snow cover (volume scattering), snow wetness, presence of ice layers, age (grain size/shape), and sea water flooding at the snow-ice interface. Due to differences in structure and composition, different types of sea ice have different polarimetric scattering behaviours. The unique coherent dual-polarimetric X-band capability of TSX imagery was used to emphasise the volume scattering through the parameters derived from entropy/alpha decomposition developed by Cloude and Pottier (1997). This method does not depend on the assumption of a particular underlying statistical distribution and is free from the physical constraints imposed by multivariate models (Singh et al. 2010).

While the conceptual theory of target decomposition was developed for quad-pol radar backscatter, it can also be applied to dual-polarised data (Cloude 2007). To derive the polarimetric decomposition parameters, we first generated the covariance matrix $\mathrm{C} 2$ of the images and then applied a $(9 \times 9$ kernel) refined Lee Filter (Lee 1981) to eliminate speckle but preserve the edge sharpness. A target decomposition technique was performed to derive the mean Alpha angle $(\bar{\alpha})$ and Entropy $(H)$. The Shannon Entropy (SE), characterised as the sum of intensity, degrees of polarisation, and the intrinsic degrees of coherence, was based on the method described by Morio et al. (2007). Correlation between SE estimates of the sea ice floe derived from TSX data acquired on November 27 and field-based surface elevation, snow depth, and freeboard was performed to discriminate the freeboard condition. For ice thickness calculation, we segregated sea ice and snow cover into generalised classes as they may impact the buoyancy model employed but not necessarily to discriminate between all the ice conditions present at that time. The sea ice thickness algorithm was based on empirical equations presented in (Xie et al. 2011) and 4 classes (i.e. deep slush layer, shallow slush layer, ice block with little snow cover, and snow cover with positive freeboard) based on the physical measurements of surface elevation, snow depth, and ice freeboard (Lewis et al. 2013). Finally, co-registration was performed on TSX imagery acquired on Nov. 27, Dec. 01, and Dec. 13. The co-registration could not be performed using floe boundaries, as these are dynamic and change rapidly, so ice blocks with very high SE values within the floe provided the tie points in the co-registration process. The root mean square (RMS) error in the co-registration of these images was less than 2 pixels (i.e. $<10 \mathrm{~m}$ ).

\subsubsection{Experimental Results}

Test sites and corresponding radar and validation data sets selected for the generation of showcases on sea ice thickness are summarised in Table 4.6.

\subsection{D Eigenvector Analysis}

The results of the entropy-alpha decomposition applied to a TSX image acquired on December 1, 2010, are shown in Fig. 4.15. Areas of low entropy commonly have a single dominant mechanism for radar backscatter as compared to areas of high entropy where multiple scattering mechanisms contribute. The alpha angle, derived from eigenvectors of the decomposition, is indicative of the average or dominant scattering mechanism. The majority of the alpha angle values are near $45^{\circ}$, suggesting that the scattering mechanism is mainly volume scattering. The extreme degrees of randomness over the open water portions of the image, which also show increased alpha angle values, are indicative of a low signalto-noise ratio.

\subsection{Sea Ice Classification and Ice Thickness Estimates}

Several data sources defined classes of SE from the Nov. 27 TSX data (coincident with the IceBell field surveys of Floe 6). These sources included the alpha channel image of entropy-alpha decomposition, the conventional $\mathrm{HH}$, and $\mathrm{VV}$ backscattering coefficients image, and the reflectivity ratio image corresponding to the ratio between $\mathrm{HH}$ and $\mathrm{VV}$ intensities. The range of SE was important in identifying areas of negative and positive freeboard where different buoyancy models were applied in sea ice thickness calculation. Figure 4.16 shows the range of SE classes as applied to the IceBell survey grid for Floe 6 for the three TSX images of the time series. A decrease in SE values over time is observed within the boundaries of the survey grid area. The declining SE relates to changing distribution of SE classes over time, thus implying that additional areas of sea water flooding (slush) were present later in the season. The ice bottom calculated from our SE-based model follows the trend of

Table 4.6 Test sites and corresponding radar and validation data selected for the generation of showcases on sea ice thickness

\begin{tabular}{l|l|l}
\hline $\begin{array}{l}\text { Application/ } \\
\text { product }\end{array}$ & Test site - Radar data & Reference data \\
\hline $\begin{array}{l}\text { Sea ice } \\
\text { thickness }\end{array}$ & Bellingshausen Sea & $\begin{array}{l}\text { Surface and snow depth surveys, electromagnetic induction thickness surveys, drilled hole } \\
\text { thickness profiles, terrestrial scanning LiDAR surveys, airborne scanning LiDAR surveys, and } \\
\text { ground penetrating radar surveys on sea ice floes. }\end{array}$ \\
\cline { 2 - 3 } & $\begin{array}{l}\text { TerraSAR-X dual-pol } \\
\text { Nov.2010-Jan. 2011 }\end{array}$ & \\
\hline
\end{tabular}




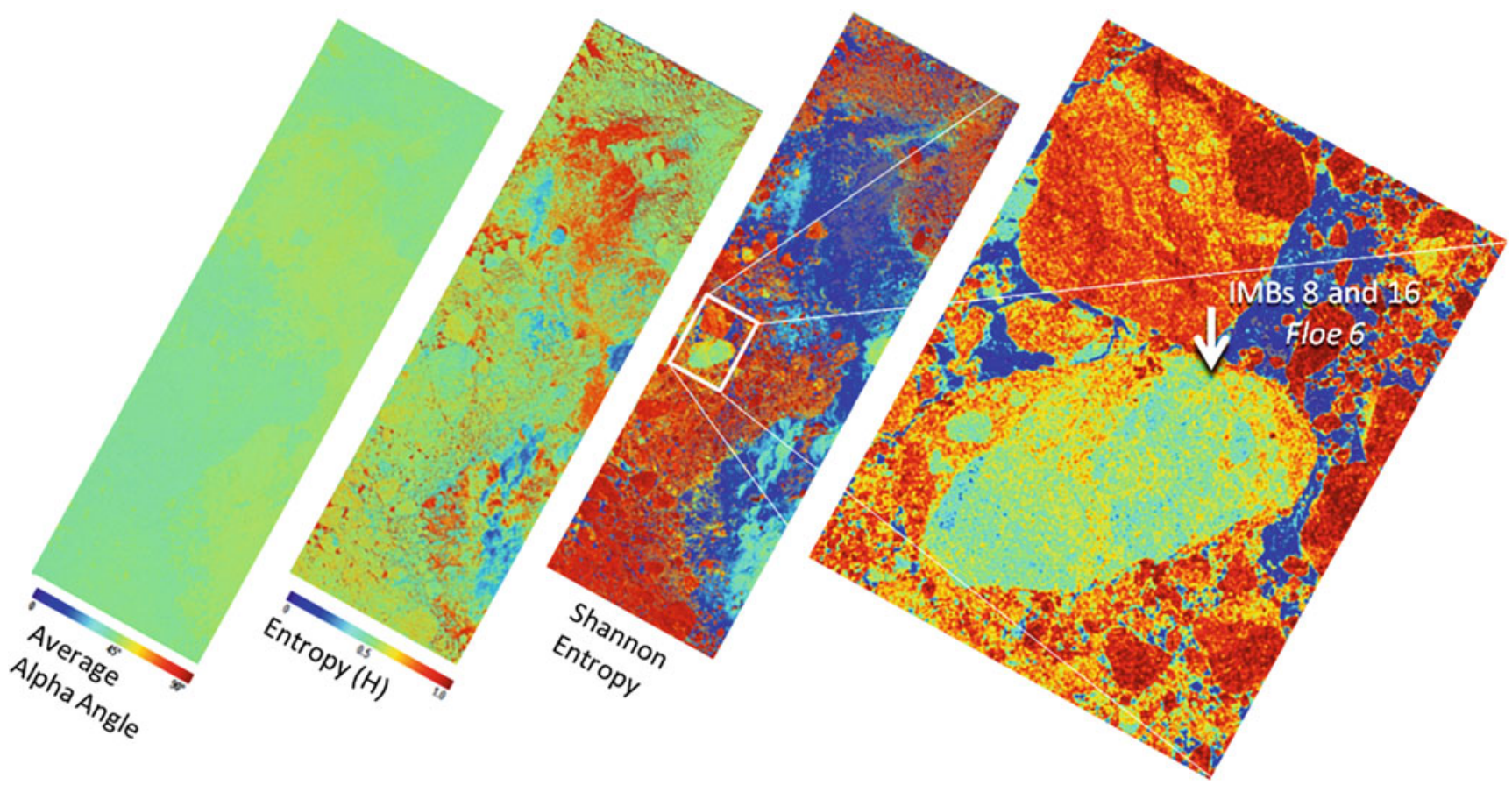

Fig. 4.15 The average Alpha angle, Entropy, and computed SE for the TSX image acquired on Dec 01, 2010. Higher SE is apparent in smaller broken floes and areas of brash ice (red) with interspersed areas of open water (dark blue). After Dec 13, the Floe 6 broke with the IMBs separated on different pieces (after Necsoiu et al. 2011; Lewis and Necsoiu 2011)
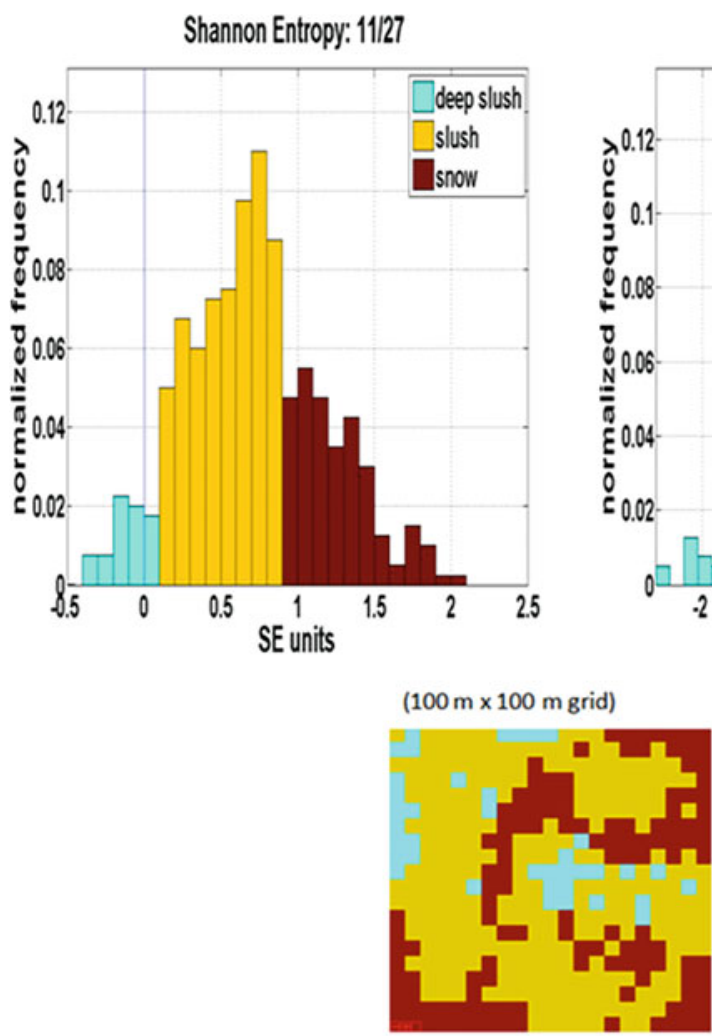

$11 / 27$

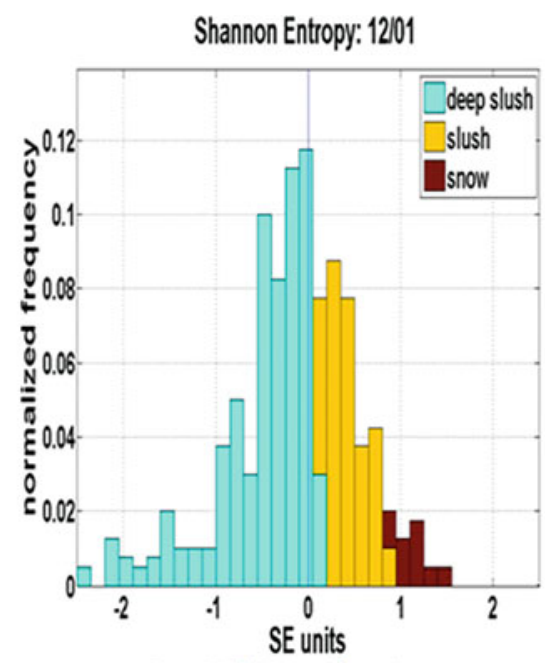

Spatial Distribution

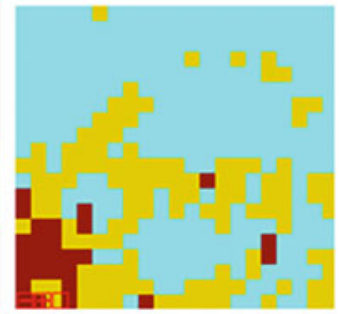

$12 / 01$

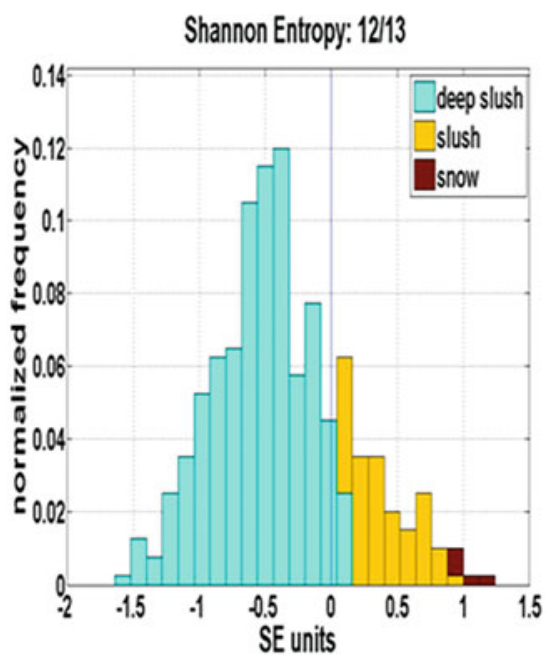

Fig. 4.16 Time series and distribution of SE for the $100 \mathrm{~m} \times 100 \mathrm{~m}$ grid survey area shown by SE class. Notice the absence of ice block class 4 present on the floe but not within the grid boundaries (this class is present elsewhere on Floe 6) 
Fig. 4.17 A 2-D profile comparison of snow and ice surface elevations and ice bottom derived from EMI measurements with ice bottom calculated from both standard buoyancy relationships and the SE-based model ice bottom (Lewis et al. 2013)

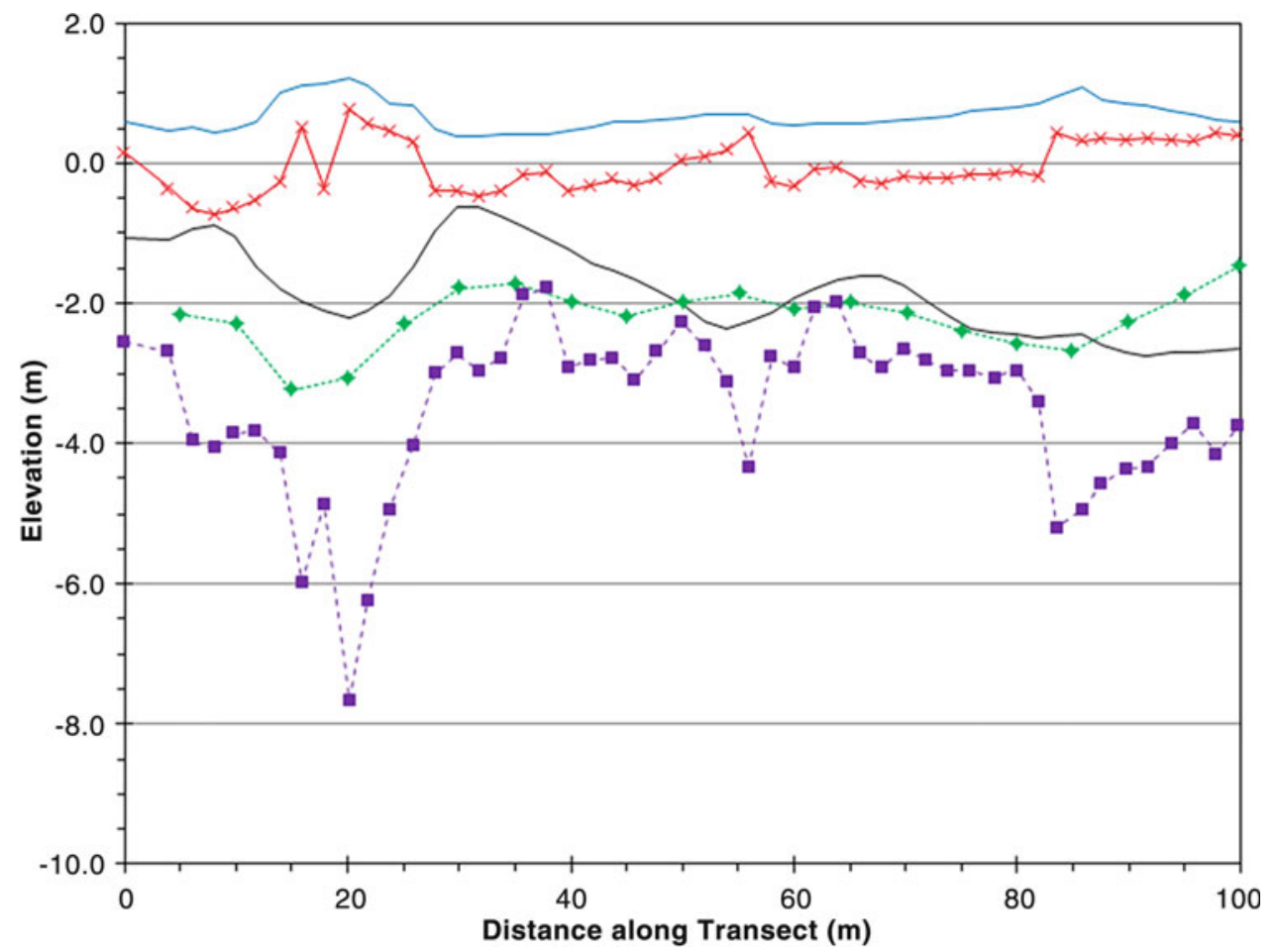

the EM-31 derived ice bottom much more closely than the simple buoyancy model used in other studies (Fig. 4.17).

\subsubsection{Discussion on the Role of Polarisation, on the Maturity of the Application and Conclusions}

Based on preliminary results, TSX dual-pol HHVV data have the potential to derive sea ice type, snow and ice thickness, and surface roughness features. Regarding sea ice interpretations, it is crucial that a detailed and direct survey of ice characteristics is performed on the sea ice floes. Essential in monitoring sea ice characteristics is the capability, provided by location of the drifting buoys, to follow sampled floes with high-resolution, narrow-swath satellite data acquisitions during the months following surface sampling. IMB sensors, with their capability to track changing surface conditions through temperature and other measurements, such as snow depth and flooding, are also essential to provide field calibration over an extended period. The methodology presented here marks an advance towards an integrated sea ice algorithm based on surface sea ice measurements (including IMBs) and TSX imagery; however, more study of polarimetric descriptors and detailed analysis of field measurements will be needed to increase the information content and to validate this approach.

\subsubsection{Acknowledgements}

This research was funded by the SwRI ${ }^{\circledR}$ internal research and development program (project 20-R8181). TerraSAR-X data was provided by DLR proposal (OCE0997). The IceBell campaign was supported by Ted Maksym (BAS) and Jeremy Wilkinson (SAMS). Special credits to Steve Ackley and Blake Weissling (University of Texas at San Antonio), Dana Floricioiu, Mihai Datcu (DLR), Shane Cloude (AEL Consultants), and Phil Hwang (SAMS).

\subsubsection{Polarimetric SAR for Classification of Sea Ice in the Baltic Sea}

\subsubsection{Introduction, Motivation, and Literature Review}

The Baltic Sea is a semi-enclosed brackish sea in Northern Europe. The average ice season extends from December into May and reaches a maximum ice extent of approximately $150,000 \mathrm{~km}^{2}$. The region is steadily busy with shipping traffic for which the ice conditions are of great importance. Conditions where wind drives the ice, causing it to form ridges or pressing it against the shoreline or entrances to harbours, are of particular concern as such regions are difficult to break into.

During 2007 to 2009, Chalmers University of Technology and the Swedish Meteorological and Hydrological Institute (SMHI) carried out the project "Improved sea ice monitoring for the Baltic Sea" (Eriksson et al. 2010), with the goal to evaluate the usefulness of new space-borne SAR instruments for the purpose of operational sea ice monitoring. Within this project, a number of SAR scenes were acquired in the northern Baltic Sea. The images were evaluated, for instance, in terms of how well different ice types could be separated, and 
how differences appear between single and dual polarisation data and between different frequency bands. The Swedish Ice Service at the SMHI participated in parts of the evaluation.

In the context of the above-mentioned project, fully polarimetric SAR data were ordered from two SAR satellite systems: The Canadian RADARSAT-2 (RS2) which utilises a C-band SAR and the Japanese Advanced Land Observing Satellite (ALOS) which carried an L-band SAR.

Fully polarimetric SAR data were collected with the NASA airborne AIRSAR system over sea ice in the Beaufort, Bering, and Chukchi Seas already in 1988. These data have been evaluated in several studies and results have been presented by a number of authors, e.g. Drinkwater et al. (1991), Ngheim et al. (1995b), and Weinbrenner et al. (1995). These studies have mainly focused on the possibilities to separate different ice types or determine sea ice thickness. Various combinations of co-polar (HH or VV) and cross-polar ( $\mathrm{HV}$ or $\mathrm{VH}$ ) backscatter values and ratios, co-polar phase, or magnitude and phase of the complex correlation between the backscatter components were evaluated. Similar studies were later done on polarimetric datasets collected at other locations with various airborne SAR systems, e.g. Greenland Sea with EMISAR in 1995 (Thomsen et al. 1998), Sea of Okhotsk with PiSAR in 1999 (Wakabayashi et al. 2004) and during the SIR-C mission with the Space Shuttle over the Weddell Sea in 1994 (Eriksson et al. 1998). In a study of the improvement of sea ice classification by means of radar polarimetry, which was published by Dierking et al. in 2004 (Dierking et al. 2004), the authors came to the conclusion that the goal of a robust, fully automated sea ice classification scheme by means of polarimetric SAR was not yet achieved.

The first satellite with a fully polarimetric SAR was ALOS, which was launched in 2006. In the last 10-15 years it also became common to include various decomposition methods in the analysis of polarimetric SAR data of sea ice. These methods often make it possible to identify how individual scattering mechanisms contribute to the total received signal. Studies that have used these methods for separation of sea ice types are, e.g., presented by Wakabayashi et al. 2004, Scheuchl et al. 2002, and more recently Gill and Yackel (2012), Doulgeris (2012), and Dierking and Wesche (2013).

The most extensive comparison between ice type classification accuracies for different combinations of polarimetric parameters is the one presented by Gill and Yackel (2012). Their evaluation for three ice types (smooth first year ice, rough first year ice, and deformed first year ice) and open water for polarimetric RS2 images indicate that no single parameter discriminates significantly $(>60 \%)$ between all these ice types, but with a combination of three parameters, an overall accuracy of up to $91 \%$ was achieved.

\subsubsection{Methodology}

In order to make a qualitative evaluation of the SAR images, a field campaign was organised to collect field data. Flights with helicopter were carried out from the Umeå Airport in Sweden. Optical and thermal infrared photos were captured by two cameras directed in the nadir direction. The optical camera had a $114^{\circ}$ diagonal angle of view, whereas the infrared camera spanned $30^{\circ}$.

The fully polarimetric SAR images were studied using $H / A / \bar{\alpha}$ decomposition (Lee and Pottier 2009; Cloude and Pottier 1997). First, we formed local estimates of the coherency matrix and multi-looked to square pixel size (in groundrange coordinates). The decomposition was performed with a $9 \times 9$ boxcar filter to minimise biases in the entropy and anisotropy estimation. A polarimetric signature analysis was carried out and was used to assess the credibility of the employed segmentation.

\subsubsection{Experimental Results}

Test sites and corresponding radar and validation data sets selected for the generation of showcases on sea ice classification in the Baltic sea are summarised in Table 4.7.

We will demonstrate the results by using examples from one RS2 image and one ALOS-PALSAR image.

Site $\mathrm{A}$ is located in image \#7, at the border between the fast ice and dense drift ice seen in Fig. 4.18. The fast ice was rugged and covered by a snow layer between 0 and $45 \mathrm{~cm}$ thick. The ice thickness was measured at one point to $110 \mathrm{~cm}$. The drift ice was densely packed and attached to the fast ice. It had a level, glossy surface with a thin snow layer of less than $2 \mathrm{~cm}$ thickness. The thickness of the drift ice was measured at two locations, to 30 and $37 \mathrm{~cm}$.

An $H / A / \bar{\alpha}$ decomposition was made on the RADARSAT- 2 image. The result shows that both the fast ice and the drift ice in this location are subject to low entropy surface scattering. The alpha parameter is slightly lower over the fast ice $\left(\sim 10^{\circ}\right.$ as compared to $\left.\sim 20^{\circ}\right)$, thus being closer to the geometrical optics limit. The entropy is lower over the fast ice as well (0.2 as compared to 0.5$)$, indicating more random scattering from the drift ice. Specular reflection, away from the radar, is presumed to occur on the flat surface of the drift ice. The returned signal is instead dominated by reflection from brine pockets and fractures in the uppermost

Table 4.7 Test sites and corresponding radar and validation data selected for the generation of showcases on sea ice classification in the Baltic sea

\begin{tabular}{l|l|l}
\hline Application/product & Test site - Radar data & Reference data \\
\hline \multirow{2}{*}{ Sea ice classification in the Baltic Sea } & Baltic Sea (Bay of Bothnia, Kvarken) & Optical and thermal infrared photos \\
\cline { 2 - 2 } & ALOS-PALSAR 2007, 2009 & \\
\cline { 2 - 2 } & RADARSAT-2 2009 & \\
\hline
\end{tabular}



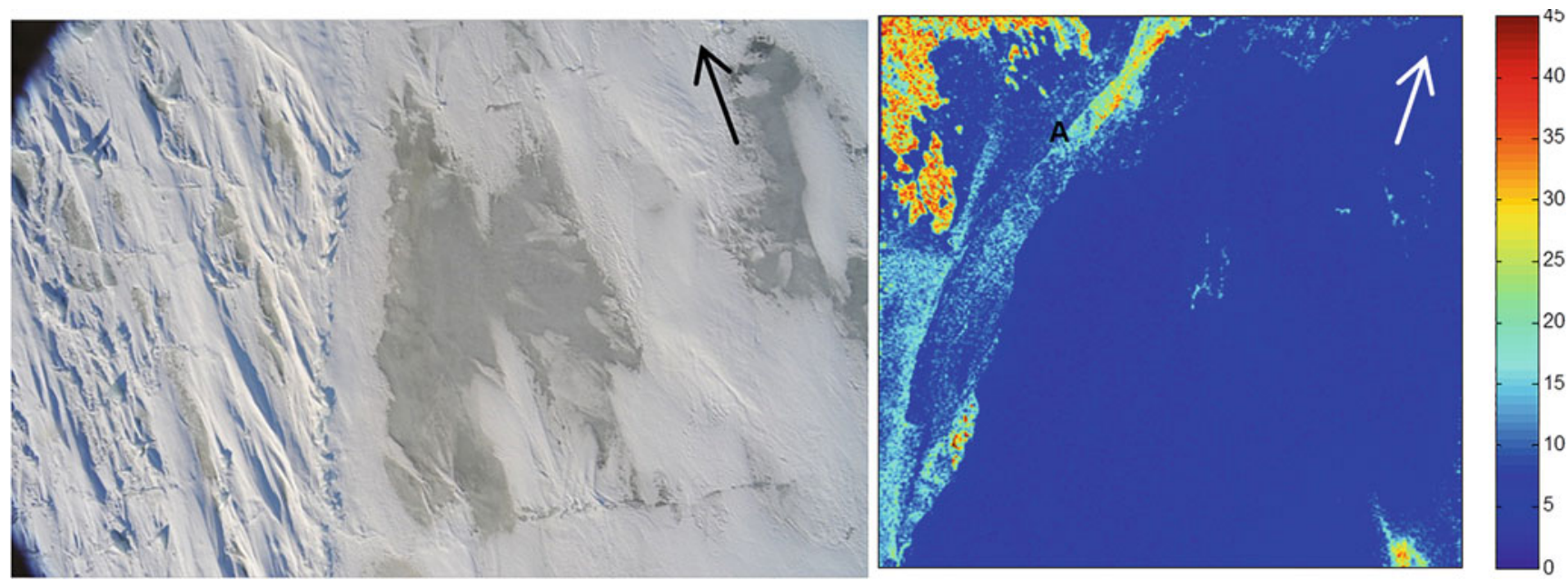

Fig. 4.18 Scene \#7. Left: Optical photo taken from helicopter in the nadir direction. The photo covers an area of $50 \times 30 \mathrm{~m}$ and shows fast ice to the left and dense drift ice to the right. Right: The alpha-parameter

from the $H / A / \alpha$-decomposition. The scene covers an area of $24 \times 24 \mathrm{~km}$. Site A is marked with letter A and is also the location of the optical photo. Arrows indicate North

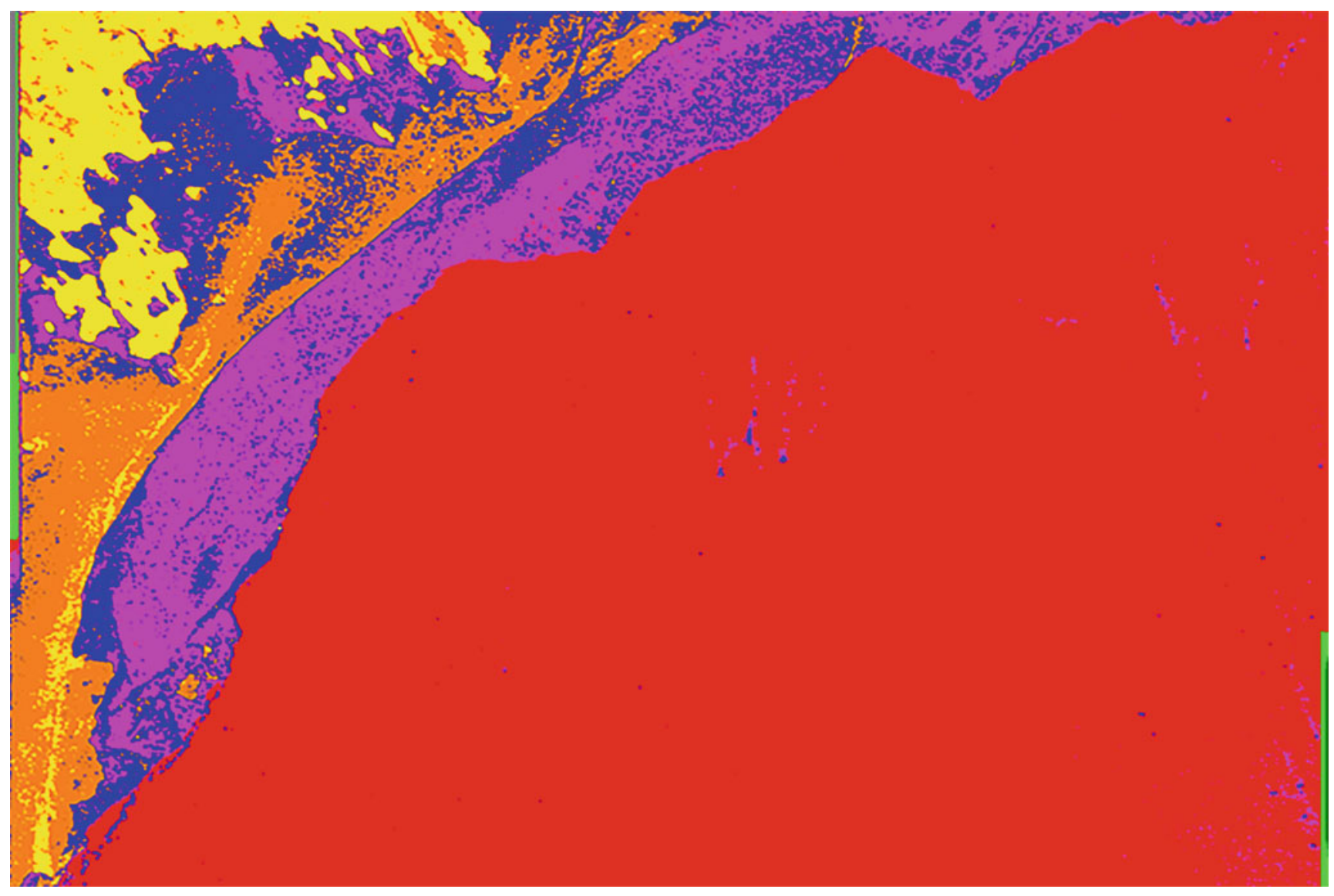

Fig. 4.19 Scene \#7. Wishart $H / \alpha$ classification where orange corresponds to fast ice, purple to drift ice, red to open water, and yellow to land areas

layer of the low-saline ice, which then explains the higher entropy and alpha values. The two ice types found in site A are believed to be representative for a much larger area, judging from the optical helicopter images. This is also in agreement with the results from a classification, shown in Fig. 4.19. The figure shows an unsupervised $H / \bar{\alpha}$ classification with eight classes, where the fast and drift ice are well distinguished. 

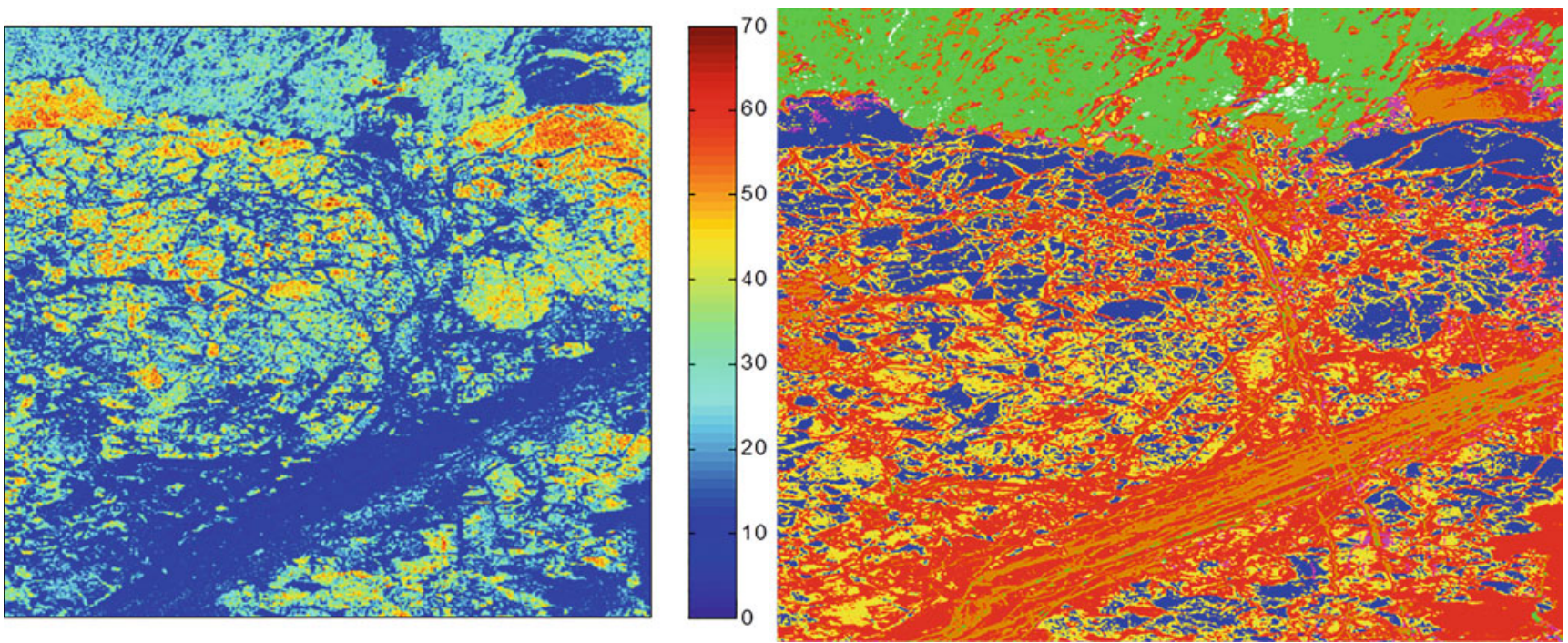

Fig. 4.20 Scene \#10. Left: The alpha-parameter from the $H / A / \alpha$-decomposition. Right: Wishart $H / \alpha$ classification (green colour is land, other colours sea ice). The scene covers an area of approximately $30 \times 50 \mathrm{~km}$ (width $\times$ height)

Figure 4.20 shows the alpha parameter obtained for scene $\# 10$ along with the Wishart $H / \alpha$ classification. The scene covers a diverse ice field with an ice concentration of approximately $90 \%$. It can be observed that volume scattering is more common in the northern parts of the scene. The Wishart $H / \bar{\alpha}$ classification identifies four major classes of ice types (blue, red, yellow, and orange). The red and orange classes are characterised by low alpha and entropy values, clearly acting as surface scatterers. The blue class is defined by alpha values in the range between $40^{\circ}$ and $50^{\circ}$, relating to volume scattering, whereas the yellow class is similar but with slightly more weight towards surface scattering. The optical helicopter images reveal that these classes are mostly level ice surfaces with no snow layer, whereas the red/yellow classes consist of snow-covered or rough ice of densely packed or consolidated floes.

\subsubsection{Comparison with Single/Dual Polarisation Data}

Sea ice is fairly well studied with single and dual polarisation data using L- and C-band SAR sensors. Fully polarimetric data may be used to study in detail the scattering mechanisms for different ice types or to improve sea ice classification for the purpose of ice charting. An experienced ice analyst can use dual polarisation data to map the ice conditions with high precision, but for automated classification this remains difficult. With fully polarimetric data, the automated classification will have an advantage because the many information channels will make manual interpretation complex.

\subsubsection{Discussion on the Role of Polarisation, on the Maturity of Application and Conclusions}

SAR polarimetry has shown potential for sea ice classification and segmentation. It is still in the early development phase, not only because of the limited spatial coverage that is insufficient for traditional operational sea ice charting services but also due to the non-trivial task to accurately relate classes with their respective ice type. The classifier must either aim for a reliable segmentation into few classes or for a detailed segmentation into many ice types with the secondary task to label each class with its actual ice type.

\subsubsection{Acknowledgements}

Data from ALOS were provided by the European Space Agency within the framework of the ALOS Data European node category-1 proposal titled Improved sea ice monitoring for the Baltic Sea (AOALO.3562). Data from RADARSAT2 were granted within the Canadian program for Science and Operational Applications Research for RADARSAT2 (SOAR), project number 3924. The Umeå Marine Science Centre in Norrbyn and Lapplandsflyg AB in Umeå are acknowledged for logistical support during the field campaigns.

\subsection{Investigation of Permafrost with Fully Polarimetric Data}

\subsubsection{Introduction, Motivation, and Literature Review}

Satellite-borne synthetic aperture radar (SAR) data are useful for estimating soil moisture and surface roughness over large areas. However, few studies have been conducted using SAR to examine permafrost areas, which have surfaces covered by low vegetation, including areas with tussocks, mosses, and low shrubs; whereas SAR data has been widely used to study mineral soil surfaces. Knowledge of the moisture levels in permafrost regions is important for monitoring the seasonal 
variability of the active layer, which is a seasonally unfrozen layer that occurs in upper part of the permafrost. The North Slope in Alaska has experienced significant changes in vegetation greenness over the past two decades (Goetz et al. 2005; Verbyla 2008), and it has been suggested that variations in soil moisture may be partly responsible for these changes. Rignot and Way (1994) showed that freeze-thaw cycles in high-latitude terrestrial ecosystems, which include permafrost regions, can be monitored using ERS-1 SAR data. Several studies have examined surface soil moisture in firedisturbed forests in Alaska using C-band SAR data; variations in soil moisture were detected by variations in the backscattering coefficient $\left(\sigma^{0}\right)$ (Kasischke et al. 2007).

PALSAR was launched in 2006 onboard ALOS. PALSAR was the first Earth observing satellite to carry a full polarimetry mode, and it provides complete radar backscattering information on both the intensity and phase of the signal. This is a significant advantage for deriving a complete understanding of the factors controlling radar backscattering in areas, especially those with complex scattering mechanisms, such as low vegetation, for which the impact would be expected to be minimal in the L-band. This is also essential for deriving robust algorithms for estimating soil moisture levels, as well as other parameters.

Here, we demonstrate how to analyse field measurement data and L-band full polarimetry data. This Section is based on (Watanabe et al. 2012).

\subsubsection{Methodology}

\subsubsection{Single-Layer Model}

Three parameters describe the primary factors affecting radar scattering mechanisms: soil moisture $(M v)$ or dielectric constant $(\varepsilon)$, root mean square (RMS) height of the soil surface $(s)$, and correlation length $(l)$. The parameters $s$ and $l$ are usually multiplied by the wave number $k(k=2 \pi / \lambda$, where $\lambda$ is the radar wavelength) to give the derived parameters $k s$ and $\mathrm{kl}$.

Several models have been suggested for estimating $M v$ from SAR data. One of the popular models is the integral equation method (IEM) (Fung 1994), which describes the behaviour of $\sigma^{0}$ for both the co-polarisation and crosspolarisation terms. For cases where $k s, k l<1.2 \sqrt{\varepsilon}$, the backscattering coefficient can be calculated using the following analytical equation:

$$
\begin{aligned}
\sigma_{q p}^{0}= & \frac{k^{2}}{2} \exp \left[-2\left(\mathrm{k}_{\mathrm{z}} \cdot s\right)^{2}\right] \\
& \times \sum_{n=1}^{\infty} s^{2 n}\left|I_{q p}^{n}\right|^{2} \frac{W^{(n)}\left(-2 k_{x, 0}\right)}{n !}
\end{aligned}
$$

where $\theta$ is the local incidence angle, $k_{z}=k \cos \theta, k_{x}=k \sin \theta$, and

$$
\begin{aligned}
I_{q p}^{n} & =\left(2 k_{z}\right)^{n} f_{q p} \exp \left(-s^{2} k_{z}{ }^{2}\right)+\frac{k_{z}{ }^{n}\left[F_{q p}\left(-k_{x}, 0\right)+F_{q p}\left(k_{x}, 0\right)\right]}{2} \\
f_{v v} & =\frac{2 R_{v v}}{\cos \theta}, f_{h h}=-\frac{2 R_{h h}}{\cos \theta} \\
F_{v v}\left(-k_{x}, 0\right)+F_{v v}\left(k_{x}, 0\right) & =\frac{2 \sin ^{2} \theta\left(1+R_{v v}\right)^{2}}{\cos \theta}\left[\left(1-\frac{1}{\varepsilon}\right)+\frac{\mu \varepsilon-\sin ^{2} \theta-\varepsilon \cos ^{2} \theta}{\varepsilon^{2} \cos ^{2} \theta}\right] \\
F_{h h}\left(-k_{x}, 0\right)+F_{h h}\left(k_{x}, 0\right) & =-\frac{2 \sin ^{2} \theta\left(1+R_{h h}\right)^{2}}{\cos \theta}\left[\left(1-\frac{1}{\mu}\right)+\frac{\mu \varepsilon-\sin ^{2} \theta-\mu \cos ^{2} \theta}{\mu^{2} \cos ^{2} \theta}\right]
\end{aligned}
$$

where $\mu$ is the magnetic permeability, $R_{h h}$ and $R_{v v}$ are Fresnel reflection coefficient, and $p$ and $q$ represent the polarisations corresponding to $h$ and $v . W^{(n)}$ is the Fourier transform of the $n$-th power of the surface correlation function; the exponential, Gaussian, and 1.5-power forms of this function are well known. Many curves observed in the field appear to follow an exponential shape generated by the exponential correlation function (Fung 1994), represented by

$$
W^{(n)}(K)=\left(\frac{l}{n}\right)\left[1+\left(\frac{K l}{n}\right)^{2}\right]^{-1.5} .
$$

Oh (2004) proposed a semi-empirical model in which some parameters were tuned using ground-based
(GB) polarimetric scatterometers and AIRSAR data obtained for various soil conditions. Three parameters are defined in this model, and the following one is used in our analysis

$$
\sigma_{V H}^{0}=0.1 M_{v}^{0.7}(\cos \theta)^{2.2}\left[1-\exp \left(-0.32(k s)^{1.8}\right)\right]
$$

The applicable range of the model is less than $3 \cdot k s$.

\subsubsection{Two-Layer Model}

The two-layer model was developed to describe more complex ground phenomena, such as the presence of vegetation, or snow on ice. Fung (1994) used four terms to represent the co-polarisation surface and volume backscattering of the two layers (see Fig. 4.21): 


\section{Two layer model}

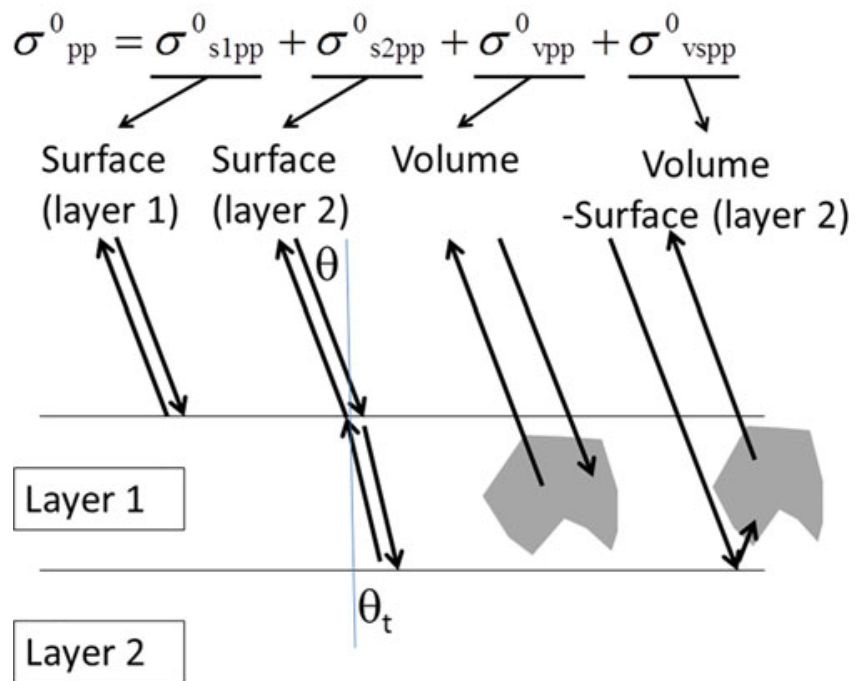

Fig. 4.21 An illustration of the terms in the 2-layer scattering model

$$
\sigma_{\mathrm{pp}}^{0}=\sigma_{\mathrm{s} 1 \mathrm{pp}}^{0}+\sigma_{\mathrm{s} 2 \mathrm{pp}}^{0}+\sigma_{\mathrm{vpp}}^{0}+\sigma_{\mathrm{vspp}}^{0}
$$

where $\sigma_{\text {s1pp }}^{0}$ describes surface scattering from layer 1 and is represented by Eq. (4.12), and $\sigma_{\text {s2pp }}^{0}$ describes surface scattering from layer 2 and is represented by

$$
\begin{aligned}
\sigma_{\mathrm{s} 2 \mathrm{pp}}^{0}= & T_{1 t}\left(\theta, \theta_{t}\right) T_{t 1}\left(\theta_{t}, \theta\right) \exp \left(\frac{-2 \tau}{\cos \theta_{t}}\right) \\
& \times \frac{\cos \theta}{\cos \theta_{t}} \sigma_{\mathrm{spp}}^{0}\left(\theta_{t}\right)
\end{aligned}
$$

where $T_{1 t}$ and $T_{t 1}$ are the transmissivity from layer 1 to 2 and from layer 2 to 1 , respectively, $\tau$ is the optical depth, and $\sigma_{\text {spp }}^{0}$ is the surface scattering at layer 2, represented by Eq. (4.12). $\sigma_{\text {vpp }}^{0}$ describes the volume scattering in layer 1 and is represented by

$\sigma_{\mathrm{vpp}}^{0}=0.5 a T_{1 t} T_{t 1} \cos \theta\left[1-\exp \left(\frac{-2 \tau}{\cos \theta_{t}}\right)\right] P_{p p}\left(\cos \theta_{t},-\cos \theta_{t} ; \pi\right)$

where $a$ is the albedo and $P_{p p}$ is element $p p$ of the phase matrix. A Rayleigh phase matrix is assumed, and $P_{h h}=P_{v v}=1.5$. The fourth term, $\sigma_{\text {vspp}}^{0}$, describes interactions between volume scattering in layer 1 and surface scattering from layer 2 . This term is very small and is negligible in most cases.

In the case of cross-polarisation, Eq. (4.15) of the Oh model is used to describe the backscattering from layer 1. Additionally, Eq. (4.16) can be modified to describe the
Table 4.8 Test sites and corresponding radar and validation data selected for the generation of showcases on permafrost characterisation

\begin{tabular}{l|l|l}
\hline $\begin{array}{l}\text { Application/ } \\
\text { product }\end{array}$ & Test site - Radar data & $\begin{array}{l}\text { Reference } \\
\text { data }\end{array}$ \\
\hline $\begin{array}{l}\text { Permafrost } \\
\text { characterisation }\end{array}$ & $\begin{array}{l}\text { Arctic National Wildlife Refuge } \\
\text { (ANWR), Alaska, USA }\end{array}$ & \\
\cline { 2 - 2 } & ALOS-PALSAR & \\
\hline
\end{tabular}

backscattering from layer 2 by inserting Eq. (4.16) for $\sigma_{\text {spp }}^{0}$, which is represented by

$$
\begin{aligned}
\sigma_{q p}^{0}= & \sigma_{\mathrm{slpq}}^{0(\text { Oh model })} \\
& +T_{1 t}\left(\theta, \theta_{t}\right) T_{t 1}\left(\theta_{t}, \theta\right) \exp \left(\frac{-2 \tau}{\cos \theta_{t}}\right) \\
& \times \frac{\cos \theta}{\cos \theta_{t}} \sigma_{s 2 q p}^{0(\text { Oh model })}\left(\theta_{t}\right) .
\end{aligned}
$$

\subsubsection{Experimental Results}

Test sites and corresponding radar and validation data sets selected for the generation of showcases on permafrost characterisation are summarised in Table 4.8.

PALSAR data acquired for the test sites (Arctic National Wildlife Refuge (ANWR), Alaska, USA) were used in this analysis. Full polarimetry mode $(\mathrm{HH}, \mathrm{HV}, \mathrm{VH}$, and VV) data was acquired on July 29, 2007, and July 31, 2008, in descending orbit. Dual polarisation mode ( $\mathrm{HH}$ and $\mathrm{HV}$ ) data was observed on August 17, 2007, 2 weeks after the observation of full polarimetry data for the test sites in ascending orbit. The off-nadir angle was $21.5^{\circ}$ for the full polarimetry mode and $34.3^{\circ}$ for the dual polarisation mode. The position of the field test sites and the physical characteristics are summarised in Table 4.8. The test sites are in the coastal tundra ecosystem of the Alaskan Arctic coastal plain. Trees were absent because of the high-latitude location $\left(70^{\circ} \mathrm{N}\right) . \mathrm{HH}$ and $\mathrm{VV}$ polarisation was dominant in the permafrost area. This means that surface backscattering was dominant. Strong radar reflections were observed for very wet areas along the small stream, and high moisture values were observed in this area (A-5 and A-6). Field observations were conducted at 6 sites in 2007 (A-1 to A-6) and 4 sites in 2008 (A-1 to A-3 and A-7). Tussocks and polygons, which are structures typical of permafrost, were observed in many tussocks in our test sites was 3 to $10 \mathrm{~cm}$ in diameter. On a larger scale, thermal contraction cracks form polygonal (mainly tetragonal) nets that cover extensive areas of arctic and subarctic regions; the polygons typically range in size from 15 to $40 \mathrm{~m}$. 
Table 4.9 Parameters derived from field measurements and from the satellite data

\begin{tabular}{|c|c|c|c|c|c|c|c|c|c|}
\hline \multirow[b]{2}{*}{ Site } & \multirow[b]{2}{*}{ Lat/Lon } & \multicolumn{7}{|c|}{ Parameters from field data collection and PalSAR } & \multirow[b]{2}{*}{ Notes } \\
\hline & & Year & $M v$ & ks & $k l$ & $\sigma_{H H}^{0}$ & $\sigma_{V H}^{0}$ & $\sigma_{V V}^{0}$ & \\
\hline \multirow[t]{2}{*}{ A-1 } & -143.66 & 2007 & 34.7 & \multirow[t]{2}{*}{0.82} & \multirow[t]{2}{*}{2.8} & -9.3 & -20.5 & -9.6 & \multirow[t]{2}{*}{ Covered with polygons well-developed tussock } \\
\hline & 69.72 & 2008 & 25.2 & & & -10.2 & -22.0 & -12.2 & \\
\hline \multirow[t]{2}{*}{ A-2 } & -143.63 & 2007 & 39.8 & \multirow[t]{2}{*}{0.68} & \multirow[t]{2}{*}{2.0} & -10.2 & -22.4 & -10.2 & \multirow[t]{2}{*}{ No polygonal structures observed } \\
\hline & 69.72 & 2008 & 46.6 & & & -11.1 & -24.1 & -9.9 & \\
\hline \multirow[t]{2}{*}{ A-3 } & -143.61 & 2007 & 41.6 & \multirow[t]{2}{*}{0.44} & \multirow[t]{2}{*}{3.4} & -11.0 & -22.8 & -11.0 & \multirow[t]{2}{*}{ No polygonal structures observed } \\
\hline & 69.72 & 2008 & 38.8 & & & -10.4 & -24.6 & -11.6 & \\
\hline \multirow[t]{3}{*}{ A-4 } & -143.62 & \multirow[t]{3}{*}{2007} & \multirow[t]{3}{*}{47.7} & \multirow[t]{3}{*}{0.71} & \multirow[t]{3}{*}{3.1} & \multirow[t]{3}{*}{-10.1} & \multirow[t]{3}{*}{-22.2} & \multirow[t]{3}{*}{-11.2} & Numerous shrub patches \\
\hline & 69.71 & & & & & & & & No polygonal structures observed \\
\hline & & & & & & & & & Well-developed tussocks \\
\hline \multirow[t]{2}{*}{ A-5 } & -143.63 & \multirow[t]{2}{*}{2007} & \multirow[t]{2}{*}{63.8} & \multirow[t]{2}{*}{0.70} & \multirow[t]{2}{*}{2.5} & \multirow[t]{2}{*}{-9.0} & \multirow{2}{*}{-21.3} & \multirow[t]{2}{*}{-9.3} & Covered with polygons \\
\hline & 69.71 & & & & & & & & Well-developed tussocks \\
\hline \multirow[t]{3}{*}{ A-6 } & -143.64 & \multirow[t]{3}{*}{2007} & \multirow[t]{3}{*}{78.9} & 1.13 & 3.2 & -8.8 & -19.3 & -8.8 & No polygonal structures observed \\
\hline & 69.71 & & & & & & & & Well-developed tussocks \\
\hline & & & & & & & & & Very wet \\
\hline A-7 & -143.60 & 2009 & 29.2 & 0.48 & 5.6 & -13.5 & -25.3 & -10.0 & \\
\hline & 69.72 & & & & & & & & \\
\hline
\end{tabular}

Mv measured in inorganic layer

\subsubsection{Data Processing}

Parameters derived from the PALSAR data and field experiment are summarised in Table 4.9. We used PALSAR data processed by the Earth Observation Center of the Japan Aerospace Exploration Agency (JAXA) and calculated the backscattering coefficient $\left(\sigma^{0}\right)$ for each polarisation. We measured $k s$ and $k l$ using a needle profilometer; the profilometer was $1-\mathrm{m}$ long for the measurements, which is 10 times longer than the typical $10-\mathrm{cm}$ correlation length at our test sites.

The 2-cm interval of needles on the profilometer was sufficiently small to have an insignificant effect on the measurement results. The surface correlation functions measured for our test sites matched well with the exponential form represented by Eq. (4.14).

The vertical cross section of the soil at site A-1 is presented in Fig. 4.22. This is a typical permafrost structure, and the soil moisture for the organic layer was measured using time-domain reflectometry (TDR-type sensor; TRIME-FM2) in 2007 and frequency-domain reflectometry (FDR-type sensor; Decagon) in 2008. The length of the probes was $15 \mathrm{~cm}$. These systems directly measured the $\varepsilon$ value, and $\varepsilon$ was converted to soil moisture using the Topp equation (Topp et al. 1980),

$$
\varepsilon_{r}=3.03+9.3 M_{v}+146 M_{v}^{2}-76.7 M_{v}^{3}
$$

The system only displays the moisture value. The value of the dielectric constant originally measured by the device was determined using this relation. The soil moisture of the sphagnum moss layer was measured for several points in site A-1 and had a value of $10.6 \%$.

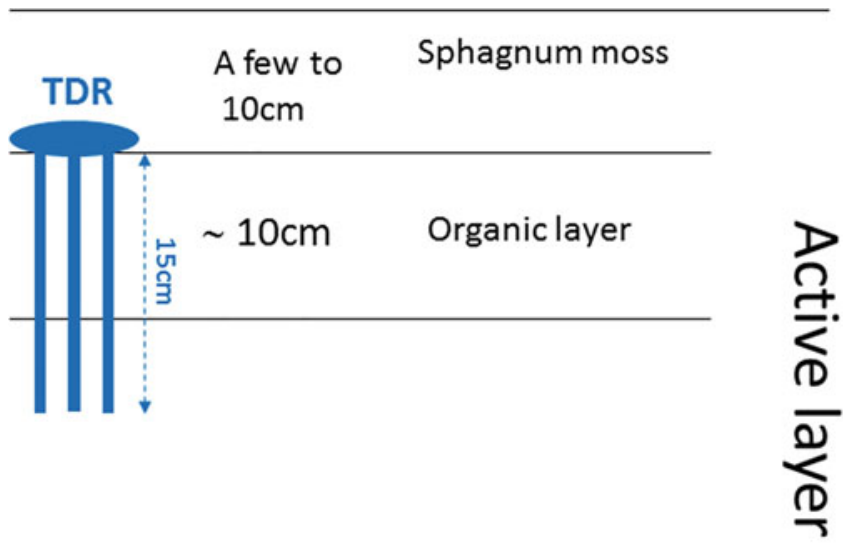

$\sim 35 \mathrm{~cm} \quad$ Minerallayer

\section{Frozen layer}

Fig. 4.22 Vertical cross section of the soil at site A-1

\subsubsection{Comparing PALSAR Data with Single-Layer Models}

The observed $\sigma^{0}$ values were compared with those estimated using the IEM/Oh model, which included the $M v$ (organic layer) and surface parameters measured in the field. The $\sigma_{\text {co- }}^{0}$ pol values were 5 to $7 \mathrm{~dB}$ lower than those calculated by the IEM model, while the $\sigma_{V H}^{0}$ values were moderately matched to values calculated using the Oh model.

Next, we calculated the $\sigma^{0}$ value assuming a $10 \%$ soil moisture value (sphagnum moss layer). The $\sigma_{\text {co-pol values }}^{0}$ 
were well matched to the IEM model, while the $\sigma^{0}{ }_{\mathrm{VH}}$ values were 3 to $6 \mathrm{~dB}$ less than those in the Oh model. There is no single-layer model that simultaneously accounts for the $\sigma_{\text {co-pol }}^{0}$ and $\sigma_{\text {cross-pol observed with PALSAR. }}^{0}$

\subsubsection{Comparing PALSAR Data with Two-Layer Models}

The 2-layer model (sphagnum moss, layer 1; organic layer, layer 2) was used to calculate $\sigma^{0}$ at the A-1 site, where a data logger was deployed to monitor moisture levels. Albedo and optical depth values were changed from 0.1 to 1 , and $\sigma^{0}$ was calculated from the two-layer model; these results were compared with PALSAR data taken with off-nadir angles of $21.5^{\circ}$ and $34.3^{\circ}$. As the sphagnum moss layer may smoothen surface roughness, a value of half the surface roughness was adopted for $k s$ in layer $1 ; k l$ was estimated from its correlation with $k s$.

Several combinations of albedo and optical depth values yielded $\sigma^{0}$ discrepancies of $<2 \mathrm{~dB}$ between PALSAR data and the results of the 2-layer model. One of the best results is presented in Fig. 4.23, which was obtained using the parameters listed in Table 4.10. The $\sigma^{0}$ values derived from the PALSAR data are plotted as squares for the full polarisation mode (off-nadir angle of $21.5^{\circ}$; incidence angle of $24^{\circ}$ ) and as circles for the dual polarisation mode (off-nadir angle of $34.3^{\circ}$; incidence angle of $38^{\circ}$ ). In this case, the 2-layer model for both co-polarisation and cross-polarisation fit the data to within $1 \mathrm{~dB}$. In the case of co-polarisation with an incident angle of $24^{\circ}$, surface scattering from layer 1 was dominant with smaller contributions expected from layer 2 and from volume scattering. In the case of crosspolarisation, scattering from layer 2 was dominant, and scattering from layer 1 (soil moisture of 10\%) was negligible.

The entropy $(\mathrm{H})$ and $\alpha$ were also calculated from the full polarimetry data. The $\alpha$ angle ranged from $13.5^{\circ}$ to $23.6^{\circ}$, and $\mathrm{H}$ ranged from 0.28 to 0.47 . These values are categorised as
Zone 9 in the $\mathrm{H} / \alpha$ classification scheme, which represents low entropy scattering processes such as surface scattering. The entropy values observed at Ulaanbaatar were 0.14 , and smaller than those observed in ANWR, although the sites have almost the same surface parameters and $M v$. A larger entropy value indicates the complexity of the scattering mechanism; therefore, the two-layer scattering model for ANWR may generate a large entropy value.

\subsubsection{Discussion on the Role of Polarimetry, on the Maturity of the Application and Conclusions}

The simultaneous collection of field data and ALOS-PALSAR fully polarimetric observations was performed in Alaska, USA (2007 and 2008). The ground surface in Alaska is covered by an active layer of permafrost consisting of a few to $10 \mathrm{~cm}$ of sphagnum moss layer and deeper organic and mineral layers.

From the analysis of field data and PALSAR data, we compiled the following results:

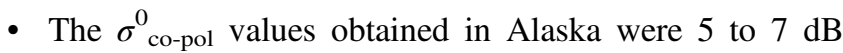
lower than those predicted by the IEM model.

- Unlike $\sigma_{\text {co-pol }}^{0}$ values, $\sigma_{\mathrm{VH}}^{0}$ values estimated from the $\mathrm{Oh}$ model are moderately well matched to those derived from the PALSAR data.

Table 4.10 Parameters for the two-layer model

\begin{tabular}{l|l|l}
\hline Parameters & Layer 1 & Layer 2 \\
\hline$M v$ & $10 \%(\varepsilon=5.3)$ & $34.7 \%(\varepsilon=20.6)$ \\
\hline$k s$ & 0.41 & 0.82 \\
\hline$k l$ & 3.88 & 2.75 \\
\hline Albedo $(a)$ & 0.1 & \\
\hline Optical depth $(\tau)$ & 0.5 & \\
\hline Frequency & $1.27 \mathrm{GHz}$ &
\end{tabular}

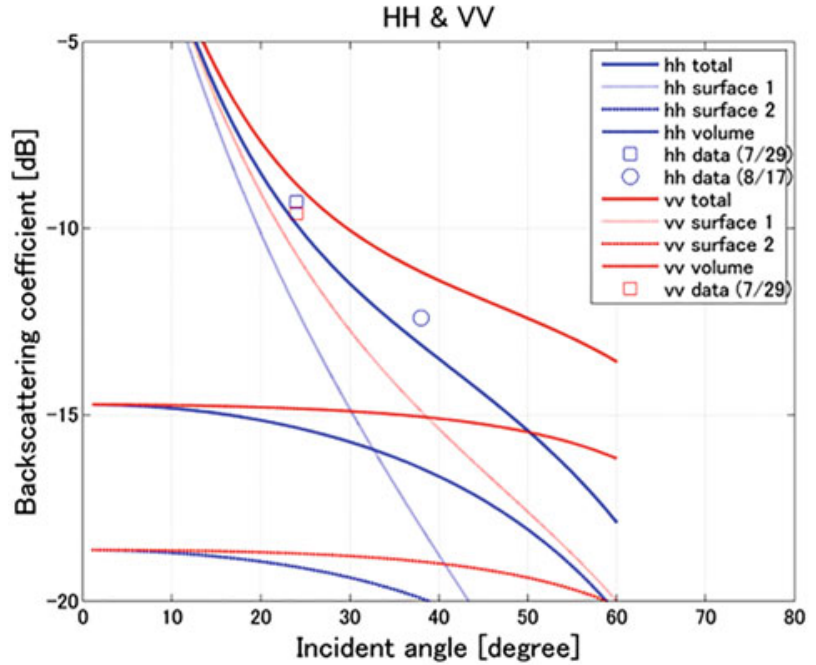

Fig. 4.23 $\sigma^{0}$ derived from the two-layer model is plotted against incidence angle. (Left panel) Co-polarisation. (Right panel) Cross-polarisation. PALSAR data are represented by squares (July 29, 2007, observations) and circles (August 17, 2007, observations) 
- Vertical depth dependency of moisture levels was observed in the field data from permafrost regions. Moisture levels of the sphagnum layer, located above the organic layer, were estimated to be about $10 \%$, while moisture levels of the underlying organic and mineral layers were $25 \%$ to $79 \%$, respectively.

From these observations, we concluded that the sphagnum moss layer plays an important role in radar backscattering processes in permafrost regions and is a main contributor to the $\sigma_{\text {co-pol }}^{0}$ backscattering component; the underlying organic and mineral layers, on the other hand, contribute to the $\sigma_{\text {cross- }}^{0}$ pol component. A two-layer model, which was applied to one of the test sites in Alaska, provided a good prediction of $\sigma^{0}$ values derived from PALSAR data obtained with off-nadir angles of $21.5^{\circ}$ and $34.3^{\circ}$, for both co-polarisation and cross-polarisation results.

Full polarimetry data describe the complete radar backscattering from a target, and it is essential for understanding the scattering mechanism from the target. If full polarimetry data is not used, it is difficult to conclude whether the two-layer model is necessary for the description of $\sigma^{0}$ in the permafrost region.

\subsubsection{Acknowledgements}

We are grateful to the graduate and undergraduate students at Sato Laboratory in Tohoku University for their assistance with field data collection. The field measurements in Alaska were funded by JAXA. This work was supported by Japan Society for the Promotion of Science (JSPS) Grants-in-Aid for Scientific Research, (S) 18106008, (B) 22404001, and (C) 21510004 .

\subsection{Summary (Table 4.11)}

\section{References}

Barnett TP, Adam JC, Lettenmaier DP (2005) Potential impacts of a warming climate on water availability in snow-dominated regions. Nature 438:303-309

Beaven SG, Lockhart GL, Gogineni SP, Hossetnmostafa AR, Jezek K, Gow AJ, Perovish DK, Fung AK, Tjuauja S (1995) Laboratory measurements of radar backscatter from bare and snow-covered saline ice sheets. Int J Remote Sens 16:851-876

Bernier M, Fortin JP (1998) The potential of time series of C-band SAR data to monitor dry and shallow snow cover. IEEE Trans Geosci Remote Sens 36:226-243

Bindschadler RA, Jezek KC, Crawford J (1987) Glaciological investigations using the synthetic aperture radar imaging system. Ann Glaciol 9:11-19

Busche T, Hajnsek I, Papathanassiou KP, Krumpen T, Rabenstein L, Hölemann J, Haas C, Willmes S (2009) Comparison of helicopterborne thin sea ice thickness profiles with polarimetric signatures of dual-pol TerraSAR-X data. In: Proceedings of IEEE 2009 International Geoscience and Remote Sensing Symposium (IGARSS)

Carlström A (1997) A microwave backscattering model for deformed first-year sea ice and comparisons with SAR data. IEEE Trans Geosci Remote Sens 35:378-391

Cloude SR (2007) The dual polarization entropy/alpha decomposition: a PALSAR case study. Paper presented at the 2007 international workshop on Science and Applications of SAR Polarimetry and Polarimetric Interferometry (POLinSAR)

Cloude SR (2009) Polarisation: applications in remote sensing. Oxford University Press, Oxford

Cloude SR, Pottier E (1997) An entropy based classification scheme for land application of polarimetric SAR. IEEE Trans Geosci Remote Sens 35:68-78

Dall J (2007) InSAR elevation bias caused by penetration into uniform volumes. IEEE Trans Geosci Remote Sens 45:2319-2324

Dall J, Papathanassiou KP, Skriver H (2003) Polarimetric SAR interferometry applied to land ice: first results. In: Proceedings of IEEE 2003 International Geoscience and Remote Sensing Symposium (IGARSS)

Dall J, Papathanassiou KP, Skriver H (2004) Polarimetric SAR interferometry applied to land ice: modelling. In: Proceedings of 2004 European Conference on Synthetic Aperture Radar (EUSAR)

Davis CH, Poznyak VI (1993) The depth of penetration in Antarctic firn at $10 \mathrm{GHz}$. IEEE Trans Geosci Remote Sens 31:1107-1111

Dierking W (1999) Multifrequency scatterometer measurements of Baltic Sea ice during EMAC-95. Int J Remote Sens 20:349-372

Table 4.11 Summary of presented application, methods and preferred system configurations for cryosphere monitoring

\begin{tabular}{l|l|l}
\hline Application & Methods and used frequency (P/L/C/X) & $\begin{array}{l}\text { Radar data preference/requirements/ } \\
\text { comments }\end{array}$ \\
\hline $\begin{array}{l}\text { Land ice extinction (internal } \\
\text { structure) }\end{array}$ & PollnSAR decomposition and inversion (P/L) & Preferred frequencies: P/L \\
\hline Snow water equivalent & PolSAR decomposition and inversion (C/X) & Preferred frequencies: X/Ku \\
\cline { 2 - 3 } & Pea ice: Observation & Dual-pol may suffice \\
\hline Sea ice: Thematic mapping & Statistical image segmentation based on PolSAR descriptors (C) & Wide swath needed \\
& $\begin{array}{l}\text { Wishart classification applied to PolSAR entropy/alpha } \\
\text { decomposition (L/C) }\end{array}$ & \\
\hline Sea ice thickness & PolSAR decompositions, segmentation and empirical models (X) & Wide swath needed \\
\hline Permafrost observation & Based on a PolSAR two-layer scattering model (L) & At X-band, dual-pol may suffice \\
\hline
\end{tabular}


Dierking W, Dall J (2007) Sea-ice deformation state from synthetic aperture radar imagery - Part I: comparison of C- and L-band and different polarization. IEEE Trans Geosci Remote Sens 45:3610-3622

Dierking W, Wesche C (2013) C-band radar polarimetry - useful for detection of icebergs in sea ice? IEEE Trans Geosci Remote Sens 52:25-37

Dierking W, Carlstrom A, Ulander LMH (1997) The effect of inhomogeneous roughness on radar backscattering from slightly deformed sea ice. IEEE Trans Geosci Remote Sens 35:147-159

Dierking W, Skriver H, Gudmandsen P (2003) SAR polarimetry for sea ice monitoring. Paper presented at the 2003 International Workshop on Science and Applications of SAR Polarimetry and Polarimetric Interferometry (POLinSAR)

Dierking W, Skriver H, Gudmandsen P (2004) On the improvement of sea ice classification by means of radar polarimetry. In: Goossens $\mathrm{R}$ (ed) Remote sensing in transition. Millepress, Rotterdam

Doulgeris AP (2012) Rethinking statistical based segmentation of sea ice. Paper presented at the ESA SeaSAR 2012 workshop

Doulgeris AP (2013) A simple and extendable segmentation method for multi-polarisation SAR images. Paper presented at the 2013 International Workshop on Science and Applications of SAR Polarimetry and Polarimetric Interferometry (POLinSAR)

Doulgeris AP, Eltoft T (2010) Scale mixture of Gaussian modelling of polarimetric SAR data. EURASIP J Adv Sig Proc 2010:1-12

Dowdeswell JA, Drewry DJ (2004) Investigations of the form and flow of ice sheets and glaciers using radio-echo sounding. Publ Rep Progr Phys 67:1821-1861

Dowdeswell JA, Unwin B, Nuttall AM, Wingham DJ (1999) Velocity structure, flow instability and mass flux on a large Arctic ice cap from satellite radar interferometry. Earth Planet Sci Lett 167:131-140

Drinkwater MR, Kwok R, Rignot E (1990) Synthetic aperture radar polarimetry of sea ice. In: Proceedings of IEEE 1990 International Geoscience and Remote Sensing Symposium (IGARSS)

Drinkwater MR, Kwok R, Winebrenner DP, Rignot E (1991) Multifrequency polarimetric synthetic aperture radar observations of sea ice. J Geophys Res 96:20679-20698

Drinkwater M, Kwok R, Rignot R, Israelsson H, Onstott RG, Winebrenner DP (1992) Potential applications of polarimetry to the classification of sea ice. Geophys Monogr Ser 68:419-430

Elachi C, Van Zyl JJ (2006) Introduction to the physics and techniques of remote sensing. Wiley, New York

Eltoft T, Fors A, Moen MA, Renner A, Doulgeris A, Gerland S, FerroFamil L (2012) A multi-polarization study of Arctic sea ice in C-band and X-band. Paper presented at the ESA SeaSAR 2012 Workshop

Eriksson L, Drinkwater M, Holt B, Valjavek E, Nortier O (1998) SIR-C polarimetric radar results from the Weddell Sea, Antarctica. In: Proceedings of IEEE 1998 International Geoscience and Remote Sensing Symposium (IGARSS)

Eriksson LEB, Borenäs $\mathrm{K}$, Dierking $\mathrm{W}$, Berg A, Santoro $\mathrm{M}$, Pemberton P, Lindh H, Karlson B (2010) Evaluation of new spaceborne SAR sensors for sea-ice monitoring in the Baltic Sea Can J Remote Sens 36:56-73

European Space Agency (2008) CoReH2O: candidate earth explorer core missions- reports for assessment. Mission Science Division, ESA-ESTEC, Noordwijk, The Netherlands, ESA SP-1313(3)

Franceschetti G, Lanari R (1999) Synthetic aperture radar processing. CRC Press, Boca Raton

Freeman A (2007) Fitting a two-component scattering model to polarimetric SAR data from forests. IEEE Trans Geosci Remote Sens 45:2583-2592

Fung AK (1994) Microwave scattering and emission models and their applications. Artech House, Norwood

Gareth Rees W (2006) Remote sensing of snow and ice. Taylor \& Francis, Boca Raton
Geldsetzer T, Yackel JJ (2009) Sea ice type and open water discrimination using dual co-polarised C-band SAR. Can J Remote Sens 35:73-84

Geldsetzer T, Mead JB, Yackel JJ, Scharien RK, Howell SEL (2007) Surface-based polarimetric C-band scatterometer for field measurements of sea ice. IEEE Trans Geosci Remote Sens 45:3405-3416

Gill JP, Yackel JJ (2012) Evaluation of C-band SAR polarimetric parameters for discrimination of first- year sea ice types. Can J Remote Sens 38:306-323

Goetz SJ, Bunn AG, Fiske GJ, Houghton RA (2005) Satellite-observed photosynthetic trends across boreal North America associated with climate and fire disturbance. Proc Natl Acad Sci U S A 102:13521-13525

Guneriussen T, Hogda KA, Johnsen H, Lauknes I (2001) InSAR for estimation of changes in snow water equivalent of dry snow. IEEE Trans Geosci Remote Sens 39:2101-2108

Hajnsek I (2001) Inversion of surface parameters using polarimetric SAR. Ph.D. thesis, Friedrich-Schiller Universität, Jena

Hajnsek I, Schoen H, Jagdhuber T, Papathanassiou KP (2007) Estimation of soil moisture under vegetation using PolInSAR: a comparison of methods. Paper presented at the AgriSAR workshop

Hoen EW (2001) A correlation-based approach to modeling interferometric radar observations of the Greenland ice sheet. Ph.D. thesis, Stanford University

Hoen EW, Zebker HA (2000) Penetration depths inferred from interferometric volume decorrelation observed over the Greenland ice sheet. IEEE Trans Geosci Remote Sens 38:2572-2583

Holmlund P, Nyman M, Petterson R, Stenberg M, Gjerde K, Gundestrup N, Hansson M, Isaksonn E, Karloef L, Winther JG, Pinglot F, Reijmer C, Thomassen M, Van de Wal R, Van der Veen C, Wilhelms F (2000) Spatial gradients in snow layering at $10 \mathrm{~m}$ temperatures at two EPICA-dronning Maud Land (Antarctica) pre-site-survey drill sites. Ann Glaciol 30:13-19

Isleifson D, Langlois A, Barber DG, Shafai L (2009) C-Band scatterometer measurements of multiyear sea ice before fall freezeup in the Canadian Arctic. IEEE Trans Geosci Remote Sens 47:1651-1661

Isleifson D, Hwang B, Barber DG, Scharien RK, Shafai L (2010) C-band polarimetric backscattering signatures of newly formed sea ice during fall freeze-up. IEEE Trans Geosci Remote Sens 48:3256-3267

Israelsson H, Askne J (1991) Analysis of polarimetric SAR observations of sea ice. In: Proceedings of IEEE 1991 International Geoscience and Remote Sensing Symposium (IGARSS)

Jackson CR, Apel JR (2004) Synthetic aperture radar marine user's manual. National Oceanic and Athmospheric Administration (NOAA)

Jezek KC, Gogineni P, Shanableh M (1994) Radar measurements of melt zones on the Greenland ice sheet. Geophys Res Lett 21:33-36

Joughin IR, Kwok R, Fahnestock MA (1998) Interferometric estimation of three-dimensional ice-flow using ascending and descending passes. IEEE Trans Geosci Remote Sens 36:25-37

Kasischke ES, Bourgeau-Chavez LL, Johnstone JF (2007) Assessing spatial and temporal variations in surface soil moisture in firedisturbed black spruce forests in Interior Alaska using spaceborne synthetic aperture radar imagery - implications for post-fire tree recruitment. Remote Sens Environ 108:42-58

Kern S, Gade M, Haas C, Pfaffling A (2006) Retrieval of thin-ice thickness using the L-band polarization ratio measured by the helicopter-borne scatterometer HELISCAT. Ann Glaciol 44:275-280

Kim JW, Kim DJ, Hwang BJ (2012) Characterization of arctic sea ice thickness using high-resolution spaceborne polarimetric SAR data. IEEE Trans Geosci Remote Sens 50:13-22

Kong JA (1986) Electromagnetic wave theory. Wiley, New York 
Kurtz NT, Markus T (2012) Satellite observations of Antarctic Sea ice thickness and volume. J Geophys Res Oceans. https://doi.org/10. 1029/2012JC008141

Kurtz NT, Markus T, Cavalieri DJ, Sparling LC, Krabill WB, Gasiewski AJ, Sonntag JG (2009) Estimation of sea ice thickness distributions through the combination of snow depth and satellite laser altimetry data. J Geophys Res Oceans. https://doi.org/10.1029/2009JC005292

Kwok R, Drinkwater M, Pang A, Rignot E (1991) Characterization and classification of sea ice in polarimetric SAR data. In: Proceedings of IEEE 1991 International Geoscience and Remote Sensing Symposium (IGARSS)

Kwok R, Nghiem SV, Yueh SH, Huynh DD (1995) Retrieval of thin ice thickness from multifrequency polarimetric SAR data. Remote Sens Environ 51:361-374

Lee JS (1981) Refined filtering of image noise using local statistics. Comput Vis Graph Image Proc 15:380-389

Lee JS, Pottier E (2009) Polarimetric radar imaging: from basics to applications. CRC Press, Boca Raton

Lee JS, Schuler DL, Ainsworth TL (2000) Polarimetric SAR data compensation for terrain azimuth slope variation. IEEE Trans Geosci Remote Sens 38:2153-2163

Lee JS, Schuler DL, Ainsworth TL, Krogager E, Kasilingam D, Boerner WM (2002) On the estimation of radar polarization orientation shifts induced by terrain slopes. IEEE Trans Geosci Remote Sens 40:30-41

Lewis MJ, Necsoiu M (2011) Seeing sea ice. In: Technology Today, SwRI

Lewis MJ, Necsoiu M, Parra J, Maksym T (2013) Evolution of Antarctic Sea ice characteristics using TerraSAR-X data. TBD

Livingstone CE, Barber DG, Spiring F, Liu W (1996) The SIMMS'93 SAR polarimetry experiment: combined surface and airborne radar measurements of winter sea ice. In: Proceedings of IEEE 1996 International Geoscience and Remote Sensing Symposium (IGARSS)

Maetzler C (1998) Microwave properties of ice and snow. In: Shmitt B et al (eds) Solar system ices. Astrophys Space Sci Library 227:241-257. Kluwer Academic Publisher

Massonnet D, Feigl KL (1998) Radar interferometry and its application to changes in the Earth's surface. Rev Geophys 36:441-500

Matsuoka T, Uratsuka S, Satake M, Nadai A, Umehara T, Maeno H, Wakabayashi H, Nishio F, Fukamachi Y (2002) Deriving Sea-ice thickness and ice types in the Sea of Okhotsk using dual-frequency airborne SAR (Pi-SAR) data. Ann Glaciol 34:429-434

Mätzler C, Strozzi T, Weise T, Floricioiu D, Rott H (1984) Microwave snowpack studies made in the Austrian Alps during the SIR-C/XSAR experiment. Int J Remote Sens 18:2505-2530

Mohr JJ, Madsen SN (1996) Application of interferometry to studies of glacier dynamics. In: Proceedings of IEEE 1996 International Geoscience and Remote Sensing Symposium (IGARSS)

Morio J, Refregier P, Goudail F, Dubois-Fernandez P, Dupuis X (2007). Application of information theory measures to polarimetric and interferometric SAR images. In: Proceedings of 2007 International Conference on Physics in Signal and Image Processing

Nakamura K, Wakabayashi H, Naoki K, Nishio F, Moriyama T, Uratsuka S (2005) Observation of sea-ice thickness in the Sea of Okhotsk by using dual-frequency and fully polarimetric airborne SAR (Pi-SAR) data. IEEE Trans Geosci Rem Sens 43:2460-2469

Necsoiu M, Lewis MJ, Parra J, Hwang P, Wilkinson J, Maksym T, Floricioiu D, Weissling B, Xie H, Ackley S (2011) Studies of Antarctic sea ice characteristics using surface sea ice measurements and TerraSAR-X data. Paper presented at the 2011 TerraSAR-X DLR Science Meeting no. 4

Nghiem SV, Yueh SH, Kwok R, Li FK (1992) Symmetry properties in polarimetric remote sensing. Radio Sci 27:693-711

Nghiem SV, Kwok R, Yueh SH, Drinkwater MR (1995a) Polarimetric signatures of sea ice -1 . Theoretical model. J Geophys Res 100:665-679
Nghiem SV, Kwok R, Yueh SH, Drinkwater MR (1995b) Polarimetric signatures of sea ice -2 . Experimental observations. J Geophys Res 100:681-698

Oh Y (2004) Quantitative retrieval of soil moisture content and surface roughness from multipolarized radar observations of bare soil surfaces. IEEE Trans Geosci Remote Sens 42:596-601

Onstott RG, Gogineni P, Gow AJ, Grenfell TC, Jezek KC, Perovich DK, Swift CT (1998) Electromagnetic and physical properties of sea ice formed in the presence of wave action. IEEE Trans Geosci Remote Sens 36:1764-1783

Paden JD, Allen CT, Gogineni S, Jezek KC, Dahl-Jensen D, Larsen LB (2007) Wideband measurements of ice sheet attenuation and basal scattering. IEEE Geosci Remote Sens Lett 2:164-168

Partington KC, Flach JD, Barber DG, Isleifson D, Meadows PJ, Verlaan P (2010) Dual-polarization C-band radar observations of sea ice in the Amundsen Gulf. IEEE Trans Geosci Remote Sens 48:2685-2691

Pisciottano I, Jagdhuber T, Hajnsek I (2011) First analysis on snow cover change using fully polarimetric TerraSAR-X data. Paper presented at the 2011 international workshop on Science and Applications of SAR Polarimetry and Polarimetric Interferometry (POLinSAR)

Rignot E, Drinkwater MR (1994) Winter Sea-ice mapping from multiparameter synthetic aperture radar. J Glaciol 40:31-45

Rignot E, Van Zyl JJ (1992) Analysis of scattering behavior and radar penetration in AIRSAR data. In: Proceedings of IEEE 1992 International Geoscience and Remote Sensing Symposium (IGARSS)

Rignot E, Way JB (1994) Monitoring freeze-thaw cycles along northsouth Alaskan transects using ERS-1 SAR. Remote Sens Environ 49:131-137

Rott H (1984) The analysis of backscattering properties from SAR data of mountain regions. IEEE J Ocean Eng 9:347-355

Rott H, Cline D, Haas C, Duguay C, Essery R, Macelloni G, Malnes J, Pulliainen J, Rebhan H, Yueh S (2008) Scientific preparations for $\mathrm{CoReH} 2 \mathrm{O}$, a dual frequency SAR mission for snow and ice observations. In: Proceedings of IEEE 2008 International Geoscience and Remote Sensing Symposium (IGARSS)

Sandven S, Johannessen OM, Kloster K (2006) Sea ice monitoring by remote sensing. Wiley, New York

Scheuchl B, Hajnsek I, Cumming IG (2002) Model-based classification of polarimetric SAR sea ice data. In: Proceedings of IEEE 2002 International Geoscience and Remote Sensing Symposium (IGARSS)

Scheuchl B, Hajnsek I, Cumming IG (2003a) Classification strategies for polarimetric SAR sea ice data. Paper presented at the 2003 International Workshop on Science and Applications of SAR Polarimetry and Polarimetric Interferometry (POLinSAR)

Scheuchl B, Cumming IG Hajnsek I (2003b) Classification of ice types from Convair-580 data of Northumberland Strait, PEI. In: Proceedings of CSA 2003 advanced SAR workshop

Scheuchl B, Caves R, Flett D, De Abreu R, Arkett M, Cumming I (2004) The potential of cross-polarization information for operational sea ice monitoring. Paper presented at the 2004 Envisat/ERS symposium

Scheuchl B, Cumming I, Hajnsek I (2005) Classification of fully polarimetric single-and dual-frequency SAR data of sea ice using the Wishart statistics. Can J Remote Sens 31:61-72

Sharma J (2010) Estimation of glacier ice extinction coefficients using long-wavelength polarimetric interferometric synthetic aperture radar. Ph.D. thesis, Karlsruhe Institute for Technology

Sharma J, Hajnsek I, Papathanassiou KP, Moreira A (2011) Polarimetric decomposition over glacier ice using long-wavelength airborne PolSAR. IEEE Trans Geosci Remote Sens 49:519-535

Shi J (2006) Snow water equivalence retrieval using $\mathrm{X}$ and $\mathrm{Ku}$ band dual-polarization radar. In: Proceedings of IEEE 2006 International Geoscience and Remote Sensing Symposium (IGARSS) 
Shi J, Dozier J (1993) Modelling and observation of polarimetric SAR response to dry snow. In: Proceedings of IEEE 1993 International Geoscience and Remote Sensing Symposium (IGARSS)

Shi J, Dozier J (1995) Inferring snow wetness using C-band data from SIRC's polarimetric synthetic aperture radar. IEEE Trans Geosci Remote Sens 33:905-914

Shi J, Dozier J (2000a) Estimation of snow water equivalent using SIR-C/X-SAR. I. Inferring snow density and subsurface properties. IEEE Trans Geosci Remote Sens 38:2465-2474

Shi J, Dozier J (2000b) Estimation of snow water equivalent using SIR-C/X-SAR. II. Inferring snow depth and particle size. IEEE Trans Geosci Remote Sens 38:2475-2488

Shi J, Davis RE, Dozier J (1993) Stereological determination of dry snow parameters for discrete microwave modelling. Ann Glaciol 17:295-299

Singh G, Yamaguchi G, Park SE, Venkataraman G (2010) Identification of snow using SAR polarimetry techniques. International Archives of the Photogrammetry, Remote Sensing and Spatial Information Science, Volume XXXVIII, Part 8, Kyoto

Skriver H, Pedersen LT (1995) Polarimetric signatures of sea ice in the Greenland Sea. In: Proceedings of IEEE 1995 International Geoscience and Remote Sensing Symposium (IGARSS)

Stebler O, Schwerzmann A, Luthi M, Meier E, Nuesch D (2005) PolInSAR observation from an alpine glacier in the cold infiltration zone at L- and P- band. IEEE Geosci Remote Sens Lett 2:357-361

Thomsen BB, Nghiem SV, Kwok R (1998) Polarimetric C-band SAR observations of sea ice in the Greenland sea. In: Proceedings of IEEE 1998 International Geoscience and Remote Sensing Symposium (IGARSS)

Tiuri M, Sihvola A, Nyfors E, Hallikaiken M (1984) The complex dielectric constant of snow at microwave frequencies. IEEE J Ocean Eng 9:377-382

Tjuatja S, Fung AK, Bredow J (1992) A scattering model for snowcovered sea ice. IEEE Trans Geosci Remote Sens 30:804-810

Topp GC, Davis JL, Annan AP (1980) Electromagnetic determination of soil water content. Water Resour Res 16:574-582

Ulaby FT, Stiles WH, Abdelrazik M (1984) Snow cover influence on backscattering from terrain. IEEE Trans Geosci Remote Sens 22:126-133

Ulaby FT, Moore RK, Fung AK (1986a) Microwave remote sensing, active and passive. Volume III: From theory to applications. Artech House, Norwood

Ulaby FT, Moore RK, Fung AK (1986b) Microwave remote sensing: active and passive. Artech House, Norwood
Uratsuka S, Maeno H, Suitz T, Fisher DA, Goto-Azuma K, Mae S (1996) Internal layering detected by microwave ice-radar in the Arctic ice cap. Nat Inst Polar Res 51:387-394

Van Zyl JJ (2011) Synthetic aperture radar polarimetry. Wiley, New York

Van Zyl JJ, Arii M, Kim Y (2008) Requirements for model-based polarimetric decompositions. In: Proceedings of 2008 European Conference on Synthetic Aperture Radar (EUSAR)

Verbyla D (2008) The greening and browning of Alaska based on 1982-2003 satellite data. Glob Ecol Biogeogeogr 17:547-555

Wakabayashi H, Sakai S (2010) Estimation of sea ice concentration in the Sea of Okhotsk using PALSAR polarimetric data. In: Proceedings of IEEE 2010 International Geoscience and Remote Sensing Symposium (IGARSS)

Wakabayashi H, Matsuoka T, Nakamura K, Nishio F (2004) Polarimetric characteristics of sea ice in the sea of okhotsk observed by airborne L-band SAR. IEEE Trans Geosci Remote Sens 42:2412-2425

Warren SG, Brandt RE (2008) Optical constants of ice from the ultraviolet to the microwave: a revised compilation. J Geophys Res Atmosp. https://doi.org/10.1029/2007JD009744

Watanabe M, Kadosaki G, Kim Y, Ishikawa M, Kushida K, Sawada Y, Tadono T, Fukudah T, Sato M (2012) Analysis of the sources of variation in L-band backscatter from terrains with permafrost. IEEE Trans Geosci Remote Sens 50:44-54

Wesche C, Dierking W (2012) Polarimetric analysis of iceberg and sea ice radar backscattering mechanisms for iceberg detection. In: Proceedings of IEEE 2012 International Geoscience and Remote Sensing Symposium (IGARSS)

Winebrenner DP, Farmer LD, Joughin IR (1995) On the response of polarimetric SAR signatures at $24 \mathrm{~cm}$ wavelength to sea ice thickness in arctic leads. Radio Sci 30:373-402

Xie H, Ackley SF, Yi D, Zwally HJ, Wagner P, Weissling B, Lewis M, Ye K (2011) Sea ice thickness distribution of the Bellingshausen Sea from surface measurements and ICESat altimetry. Deep Sea Res Part II. Topic Stud Oceanogr 58:1039-1051

Yi D, Zwally HJ, Robbins J (2011) ICESat observations of seasonal and interannual variation of sea-ice freeboard and estimated thickness in the Weddell Sea. Ann Glaciol 52:43-51

Zebker HA, Villasenor J (1992) Decorrelation in interferometric radar echoes. IEEE Trans Geosci Remote Sens 30:950-959

Zwally HJ, Yi D, Kwok R, Zhao Y (2008) ICESat measurements of sea ice freeboard and estimates of sea ice thickness in the Weddell Sea. J Geophys Res Oceans. https://doi.org/10.1029/2007JC004284

Open Access This chapter is licensed under the terms of the Creative Commons Attribution 4.0 International License (http://creativecommons.org/ licenses/by/4.0/), which permits use, sharing, adaptation, distribution and reproduction in any medium or format, as long as you give appropriate credit to the original author(s) and the source, provide a link to the Creative Commons license and indicate if changes were made.

The images or other third party material in this chapter are included in the chapter's Creative Commons license, unless indicated otherwise in a credit line to the material. If material is not included in the chapter's Creative Commons license and your intended use is not permitted by statutory regulation or exceeds the permitted use, you will need to obtain permission directly from the copyright holder.

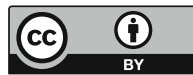

